\title{
Advanced source apportionment of size-resolved trace elements at multiple sites in London during winter
}

\author{
S. Visser ${ }^{1}$, J. G. Slowik ${ }^{1}$, M. Furger ${ }^{1}$, P. Zotter ${ }^{1, a}$, N. Bukowiecki ${ }^{1}$, F. Canonaco ${ }^{1}$, U. Flechsig ${ }^{2}$, K. Appel ${ }^{3, b}$, \\ D. C. Green ${ }^{4}$, A. H. Tremper ${ }^{4}$, D. E. Young ${ }^{5, \mathrm{c}}$, P. I. Williams ${ }^{5,6}$, J. D. Allan ${ }^{5,6}$, H. Coe ${ }^{5}$, L. R. Williams ${ }^{7}$, C. Mohr ${ }^{8, d}$, \\ L. Xu ${ }^{9}$, N. L. Ng ${ }^{9,10}$, E. Nemitz ${ }^{11}$, J. F. Barlow ${ }^{12}$, C. H. Halios ${ }^{12}$, Z. L. Fleming ${ }^{13}$, U. Baltensperger ${ }^{1}$, and \\ A. S. H. Prévôt ${ }^{1}$ \\ ${ }^{1}$ Laboratory of Atmospheric Chemistry, Paul Scherrer Institute, Villigen, Switzerland \\ ${ }^{2}$ Swiss Light Source, Paul Scherrer Institute, Villigen, Switzerland \\ ${ }^{3}$ HASYLAB, DESY Photon Science, Hamburg, Germany \\ ${ }^{4}$ Analytical and Environmental Sciences, King's College London, London, UK \\ ${ }^{5}$ School of Earth, Atmospheric and Environmental Sciences, University of Manchester, Manchester, UK \\ ${ }^{6}$ National Centre for Atmospheric Science, University of Manchester, Manchester, UK \\ ${ }^{7}$ Aerodyne Research, Inc., Billerica, MA, USA \\ ${ }^{8}$ Department of Atmospheric Sciences, University of Washington, Seattle, WA, USA \\ ${ }^{9}$ School of Chemical and Biomolecular Engineering, Georgia Institute of Technology, Atlanta, GA, USA \\ ${ }^{10}$ School of Earth and Atmospheric Sciences, Georgia Institute of Technology, Atlanta, GA, USA \\ ${ }^{11}$ Centre for Ecology and Hydrology, Penicuik, Midlothian, Scotland \\ ${ }^{12}$ Department of Meteorology, University of Reading, Reading, UK \\ ${ }^{13}$ National Centre for Atmospheric Science, Department of Chemistry, University of Leicester, Leicester, UK \\ ${ }^{a}$ now at: Lucerne School of Engineering and Architecture, Bioenergy Research, Lucerne University of Applied Sciences and \\ Arts, Horw, Switzerland \\ ${ }^{\mathrm{b}}$ now at: European XFEL, Hamburg, Germany \\ ${ }^{c}$ now at: Department of Environmental Toxicology, University of California, Davis, CA, USA \\ ${ }^{d}$ now at: Institute of Meteorology and Climate Research, Karlsruhe Institute of Technology, Karlsruhe, Germany
}

Correspondence to: J. G. Slowik (jay.slowik@psi.ch)

Received: 2 March 2015 - Published in Atmos. Chem. Phys. Discuss.: 26 May 2015

Revised: 30 August 2015 - Accepted: 21 September 2015 - Published: 12 October 2015

\begin{abstract}
Trace element measurements in $\mathrm{PM}_{10-2.5}$, $\mathrm{PM}_{2.5-1.0}$ and $\mathrm{PM}_{1.0-0.3}$ aerosol were performed with $2 \mathrm{~h}$ time resolution at kerbside, urban background and rural sites during the ClearfLo winter 2012 campaign in London. The environment-dependent variability of emissions was characterized using the Multilinear Engine implementation of the positive matrix factorization model, conducted on data sets comprising all three sites but segregated by size. Combining the sites enabled separation of sources with high temporal covariance but significant spatial variability. Separation of sizes improved source resolution by preventing sources occurring in only a single size fraction from having too small a contribution for the model to resolve. Anchor profiles were
\end{abstract}

retrieved internally by analysing data subsets, and these profiles were used in the analyses of the complete data sets of all sites for enhanced source apportionment.

A total of nine different factors were resolved (notable elements in brackets): in $\mathrm{PM}_{10-2.5}$, brake wear $(\mathrm{Cu}, \mathrm{Zr}, \mathrm{Sb}$, $\mathrm{Ba})$, other traffic-related $(\mathrm{Fe})$, resuspended dust $(\mathrm{Si}, \mathrm{Ca})$, sea/road salt $(\mathrm{Cl})$, aged sea salt $(\mathrm{Na}, \mathrm{Mg})$ and industrial $(\mathrm{Cr}, \mathrm{Ni})$; in $\mathrm{PM}_{2.5-1.0}$, brake wear, other traffic-related, resuspended dust, sea/road salt, aged sea salt and S-rich (S); and in $\mathrm{PM}_{1.0-0.3}$, traffic-related $(\mathrm{Fe}, \mathrm{Cu}, \mathrm{Zr}, \mathrm{Sb}, \mathrm{Ba})$, resuspended dust, sea/road salt, aged sea salt, reacted $\mathrm{Cl}(\mathrm{Cl})$, S-rich and solid fuel $(\mathrm{K}, \mathrm{Pb})$. Human activities enhance the kerb-to-rural concentration gradients of coarse aged sea salt, 
typically considered to have a natural source, by $1.7-2.2$. These site-dependent concentration differences reflect the effect of local resuspension processes in London. The anthropogenically influenced factors traffic (brake wear and other traffic-related processes), dust and sea/road salt provide further kerb-to-rural concentration enhancements by direct source emissions by a factor of 3.5-12.7. The traffic and dust factors are mainly emitted in $\mathrm{PM}_{10-2.5}$ and show strong diurnal variations with concentrations up to 4 times higher during rush hour than during night-time. Regionally influenced Srich and solid fuel factors, occurring primarily in $\mathrm{PM}_{1.0-0.3}$, have negligible resuspension influences, and concentrations are similar throughout the day and across the regions.

\section{Introduction}

Acute and chronic exposure to trace elements in ambient aerosols induces adverse respiratory and cardiovascular health effects (WHO, 2013). Brunekreef and Forsberg (2005) and Neuberger et al. (2004) reveal different mortality and morbidity effects for exposure to individual particle size fractions such as $\mathrm{PM}_{10-2.5}, \mathrm{PM}_{2.5-1.0}$ and $\mathrm{PM}_{1.0}$ (particulate matter with an aerodynamic diameter, $d$, of 10 to $2.5,2.5$ to 1.0 and smaller than $1.0 \mu \mathrm{m}$, respectively). These particles are emitted into the atmosphere by different sources.

The major source of PM in most urban areas is road traffic, comprising exhaust and non-exhaust (abrasion and resuspension) contributions (Denier van der Gon et al., 2013; Pant and Harrison, 2013). Other sources include industrial activities, fossil fuel use and biomass burning for heating and energy production, crustal material, sea salt, and cooking, as well as contributions of secondary inorganic and organic aerosols (EEA, 2010; Viana et al., 2008; Zhang et al., 2011). Source apportionment by positive matrix factorization (PMF; Paatero and Tapper, 1994) is a powerful tool to quantify sources based on trace element measurements. Many studies have applied PMF on either elements alone or in combination with other species, such as carbon species and inorganic ions (Amato et al., 2013; Gu et al., 2011; Hammond et al., 2008; Vedal et al., 2009; Yang et al., 2013; Zhang et al., 2013). However, such measurements are typically performed only for a single size fraction and with $24 \mathrm{~h}$ time resolution, preventing the study of diurnal behaviours of emission sources and short-term changes in air pollution exposure levels. Anthropogenic sources such as traffic $(\mathrm{Fe}, \mathrm{Cu}, \mathrm{Zn}, \mathrm{Ba})$, resuspension $(\mathrm{Al}, \mathrm{Si}, \mathrm{Ca})$ and biomass burning for home heating $(\mathrm{S}, \mathrm{K})$ typically show distinct diurnal variations, while regional and natural sources such as secondary sulfate (S) and sea salt $(\mathrm{Na}, \mathrm{Mg}, \mathrm{Cl})$ usually exhibit small diurnal variability (Bukowiecki et al., 2010; Dall'Osto et al., 2013; Viana et al., 2013). Elements in different size fractions typically serve as markers for different sources. $\mathrm{S}$ from secondary sulfate for example is mainly found in $\mathrm{PM}_{1.0}$, whereas $\mathrm{PM}_{10-1.0}$ $\mathrm{S}$ can indicate sea salt and/or mineral sulfate (Mazzei et al.,
2007). $\mathrm{PM}_{1.0} \mathrm{~K}$ mostly originates from wood burning, but is attributed to dust in $\mathrm{PM}_{10-1.0}$ (Viana et al., 2008). It is vital to understand the extent to which emission sources affect air quality, especially in urban areas, where the global population has increased from $34 \%$ (in 1960) to $56 \%$ (in 2014) and is expected to grow further (WHO, 2014).

Only a limited number of studies have applied PMF to explore trace element emission sources across multiple sites or size fractions, or with high time resolution (Bukowiecki et al., 2010; Clements et al., 2014; Dall'Osto et al., 2013; Minguillón et al., 2014; Taiwo et al., 2014). Karanasiou et al. (2009) showed a higher degree of source separation by applying PMF on combined $\mathrm{PM}_{10}$ and $\mathrm{PM}_{2}$ data than on $\mathrm{PM}_{10}$ data alone, due to a lack of variability in the sum of $\mathrm{PM}_{10}$ and $\mathrm{PM}_{2}$ concentrations of certain key tracers. The Multilinear Engine solver (ME-2; Paatero, 1999) improves on conventional PMF analyses by allowing complete and efficient exploration of the solution space, facilitating source separation. Amato et al. (2009a) and Sturtz et al. (2014) used ME-2 to achieve improved source separation by requiring the solution to be consistent with local emission profiles and providing environmentally reasonable element ratios within factor profiles. Some caution is needed when combining sites in PMF, because one needs to assume that the chemical profiles of the resolved sources do not vary significantly between the sites. This prerequisite is usually valid if the sites are only a few kilometres apart (Dall'Osto et al., 2013).

$\mathrm{PM}_{10}$ concentrations in London frequently exceed the legal daily limit of $50 \mathrm{\mu g} \mathrm{m}^{-3}$ (permitted exceedances per year of 35). These exceedances are caused by local and regional emission sources in combination with meteorological factors (Charron and Harrison, 2005; Harrison and Jones, 2005; Harrison et al., 2008; Jones et al., 2010). A better understanding of the temporal behaviour of emission sources throughout the city is needed. The objective of this study is to characterize the environment-dependent variability of emissions by source apportionment of size-resolved trace elements measured simultaneously at three sites. We apply the ME-2 implementation of the PMF model to $2 \mathrm{~h}$ element concentrations measured at two urban sites in London (Marylebone Road and North Kensington) and one rural site southeast of London (Detling), United Kingdom (UK), during the ClearfLo (Clean Air for London) field campaign (Bohnenstengel et al., 2015). PMF analysis is conducted on data sets comprising all three sites but analysed separately for each size $\left(\mathrm{PM}_{10-2.5}, \mathrm{PM}_{2.5-1.0}\right.$ and $\left.\mathrm{PM}_{1.0-0.3}\right)$. We demonstrate that rotational control of the solutions using anchor profiles in ME-2 is essential for a successful source apportionment. This approach results in enhanced source separation compared to using unconstrained PMF. We investigate the size dependence of sources such as traffic, resuspended dust, and sea salt and also identify sources unique to particular size fractions. 


\section{Methods}

\subsection{Measurement sites and instrumentation}

Measurements were conducted as part of the ClearfLo project (http://www.clearflo.ac.uk/), a multinational collaboration to investigate the processes driving air quality in and around London (Bohnenstengel et al., 2015). This study focuses on the winter intensive observation period (IOP), which took place from 6 January to 11 February 2012. Trace element measurements were conducted at kerbside, urban background and rural sites, at or near permanent air quality measurement stations of the Automatic Urban and Rural Network (AURN) or Kent and Medway Air Quality Monitoring Network (see Fig. 1). The kerbside site was located at Marylebone Road (MR; lat 51 $31^{\prime} 21^{\prime \prime} \mathrm{N}$, long $0^{\circ} 09^{\prime} 17^{\prime \prime} \mathrm{W}$ ) at the southern side of a street canyon (Charron and Harrison, 2005). Measurements were performed at $1 \mathrm{~m}$ from a six-lane road with a traffic flow of $\sim 73000$ vehicles per day $(15 \%$ heavy duty vehicles; traffic counts by vehicle group from road sensors (number of vehicles per $15 \mathrm{~min}$ )). A signalcontrolled junction at $200 \mathrm{~m}$ and a heavily used pedestrian light-controlled crossing at $65 \mathrm{~m}$ from the site resulted in frequent braking and stationary vehicle queues in front of the site. The urban background site, the main sampling site during ClearfLo, was located at the grounds of the Sion Manning Secondary School in North Kensington (NK; lat $51^{\circ} 31^{\prime} 21^{\prime \prime} \mathrm{N}$, long $0^{\circ} 12^{\prime} 49^{\prime \prime} \mathrm{W}$ ). Although the site is in a suburban area about $4.1 \mathrm{~km}$ west of MR that experiences heavy traffic, measurements took place away from main roads, and this site is representative of the urban background air quality in London (Bigi and Harrison, 2010). The rural site was situated at approximately $45 \mathrm{~km}$ to the southeast of downtown London at the Kent Showgrounds at Detling (DE; lat $51^{\circ} 18^{\prime} 07^{\prime \prime} \mathrm{N}$, long $0^{\circ} 35^{\prime} 22^{\prime \prime} \mathrm{E}$ ) on a plateau at 200 ma.s.l. surrounded by fields and villages (Mohr et al., 2013). A busy road with a traffic flow of $\sim 42000$ vehicles per day (Department for Transport, 2014) is located approximately $150 \mathrm{~m}$ south of the site.

Aerosols were sampled by rotating drum impactors (RDIs) with $2 \mathrm{~h}$ time resolution and a flow rate of $1 \mathrm{~m}^{3} \mathrm{~h}^{-1}$, and were segregated by size into $\mathrm{PM}_{10-2.5}$ (coarse), $\mathrm{PM}_{2.5-1.0}$ (intermediate) and $\mathrm{PM}_{1.0-0.3}$ (fine) fractions. Trace element composition of the RDI samples was determined by synchrotron radiation-induced X-ray fluorescence spectrometry (SR-XRF) at the X05DA beamline (Flechsig et al., 2009) at the Swiss Light Source (SLS), Paul Scherrer Institute (PSI), Villigen PSI, Switzerland, and at Beamline L at the Hamburger Synchrotronstrahlungslabor (HASYLAB), Deutsches Elektronen-Synchrotron (DESY), Hamburg, Germany (beamline dismantled November 2012). In total 25 elements were quantified $(\mathrm{Na}, \mathrm{Mg}, \mathrm{Al}, \mathrm{Si}, \mathrm{P}, \mathrm{S}, \mathrm{Cl}, \mathrm{K}, \mathrm{Ca}$, $\mathrm{Ti}, \mathrm{V}, \mathrm{Cr}, \mathrm{Mn}, \mathrm{Fe}, \mathrm{Ni}, \mathrm{Cu}, \mathrm{Zn}, \mathrm{Br}, \mathrm{Sr}, \mathrm{Zr}, \mathrm{Mo}, \mathrm{Sn}, \mathrm{Sb}, \mathrm{Ba}$, $\mathrm{Pb}$ ). Details of the RDI-SR-XRF analysis are described in

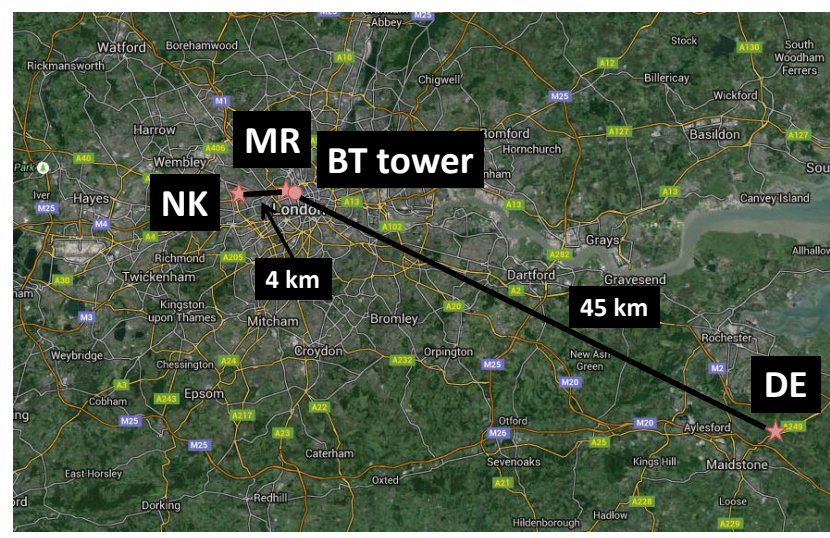

Figure 1. Map of southeastern UK. Indicated are the sampling sites MR (kerbside site Marylebone Road), NK (urban background site North Kensington), DE (rural site Detling), and the elevated BT Tower site for meteorological measurements (adapted from Google Maps).

Visser et al. (2015) and in previous application examples in Bukowiecki et al. (2010) and Richard et al. (2011).

Additional measurements discussed in this paper are briefly described here. Aerosol mass spectrometers (Aerodyne Research, Inc., Billerica, MA, USA) were deployed at MR (5 min resolution), NK (5 min sampling interval every $30 \mathrm{~min}$ ) and $\mathrm{DE}$ (2 min resolution) to characterize the nonrefractory submicron aerosol components (organic matter, sulfate, nitrate, ammonium, chloride; DeCarlo et al., 2006; Jimenez et al., 2009); a quadrupole AMS was deployed at MR; and a high-resolution time-of-flight AMS was deployed at NK and DE. Particle light absorption was derived with seven-wavelength Aethalometers $(\lambda=370-950 \mathrm{~nm}$, model AE 31, Magee Scientific; 5 min resolution) at NK (3.5 $\mu \mathrm{m}$ cyclone) and DE (2.5 $\mu \mathrm{m}$ cyclone). The measured absorption was apportioned to traffic and wood burning based on the absorption coefficients at $\lambda=470$ and $950 \mathrm{~nm}$, assuming absorption exponents of 1 and 2 for traffic and wood burning emissions, respectively (Crilley et al., 2015; Mohr et al., 2013; Sandradewi et al., 2008). At MR and NK, $\mathrm{NO}_{x}$ measurements were performed with $\mathrm{NO}_{x}$ chemiluminescent analysers (API, A Series, model M200A; 15 min resolution). At DE, $\mathrm{NO}$ (Thermo Scientific 42i analyser) and $\mathrm{NO}_{2}$ (Aerodyne CAPS-NO $\mathrm{N}_{2}$ and QCL-76-D) data were collected and summed to obtain total $\mathrm{NO}_{x}$ concentrations (1 min resolution). Wind direction and wind speed data for the two city sites were taken from the nearby BT Tower, where sonic anemometers $(20 \mathrm{~Hz})$ were placed at the top of an open lattice scaffolding tower of $18 \mathrm{~m}$ height on top of the main structure $\left(190.8 \mathrm{ma.g} .1\right.$; ; lat $51^{\circ} 31^{\prime} 17^{\prime \prime} \mathrm{N}$, long $0^{\circ} 08^{\prime} 19^{\prime \prime} \mathrm{W}$; 30 min resolution; Wood et al., 2010), while local data were used at DE. Relative humidity (RH) data at NK were derived with a Vaisala WXT sensor (5 min resolution). Finally, the UK Met Office's Numerical Atmospheric Modelling Environment (NAME) dispersion model (Jones et al., 2007) 
provided back trajectory simulations for analysis of air mass origins (Bohnenstengel et al., 2015).

\subsection{Positive matrix factorization}

PMF is a powerful source apportionment method to describe measurements, using the bilinear factor model (Paatero and Tapper, 1994)

$x_{i j}=\sum_{k=1}^{p} g_{i k} f_{k j}+e_{i j}$,

where $x_{i j}$ is the $j$ th species concentration measured in the $i$ th sample, $g_{i k}$ is the contribution of the $k$ th source to the $i$ th sample (factor time series) and $f_{k j}$ is the concentration of the $j$ th species in the $k$ th source (factor profiles). The part of the data remaining unexplained by the model is represented by the residual matrix $e_{i j}$. The entries of $g_{i k}$ and $f_{k j}$ (required to be non-negative) are fit using a least-squares algorithm that iteratively minimizes the objective function $Q$ :

$Q=\sum_{i=1}^{n} \sum_{j=1}^{m}\left(\frac{e_{i j}}{\sigma_{i j}}\right)^{2}$,

where $\sigma_{i j}$ are the measurement uncertainties.

The PMF model solution is subject to rotational ambiguity; that is, different solutions may be found having similar values of $Q$ (Paatero et al., 2002). This ambiguity can be reduced within the ME-2 algorithm by adding a priori information into the PMF model (e.g. source profiles) to reduce the available rotational space and direct the solution towards a unique, optimized and environmentally meaningful solution.

In this study, trace element source apportionment is performed using the ME-2 implementation of PMF (Paatero, 1999), with configuration and analysis in the SoFi (Source Finder) toolkit (Canonaco et al., 2013) for the IGOR Pro software environment (WaveMetrics, Inc., Portland, OR, USA). The ME-2 solver executes the PMF algorithm in a similar way to the PMF solver (Paatero and Tapper, 1994) but has the advantage that the full rotational space is accessible. One way to efficiently explore this space is with the $a$-value approach. Here one or more factor profiles are constrained by the scalar $a$, which defines how much the resolved factors are allowed to deviate from the input "anchor" profiles, according to

$f_{j, \text { solution }}=f_{j} \pm a \times f_{j}$,

where $a$ can be set between 0 and 1 . If, for example, $a=0.1$, all elements in the profile are allowed to vary within $\pm 10 \%$ of the input factor profile. For clarity, we here use the term "ME-2" to refer to solving the PMF model with the ME-2 solver using the $a$-value approach, whereas the term "unconstrained ME-2" refers to solving the PMF model using the ME-2 solver but without a priori constraints on the solution.
These algorithms require both a data matrix $\left(x_{i j}, 25\right.$ elements measured with $2 \mathrm{~h}$ time resolution) and a corresponding uncertainty matrix $\left(\sigma_{i j}\right)$. Uncertainties that uniformly affect an entire row or column of the data matrix (e.g. RDI flow rate, absolute or relative calibration) do not alter the PMF solution and are thus not considered in constructing the uncertainty matrix. Uncertainties are calculated according to Eq. (4) and account for the detector counting efficiency $\left(\sigma_{\text {Det }, i j}\right)$ and the energy calibration of an X-ray line as function of detector channel $\left(\sigma_{\mathrm{EC}, i j}\right)$ :

$\sigma_{i j}=\sqrt{\sigma_{\mathrm{Det}, i j}^{2}+\sigma_{\mathrm{EC}, i j}^{2}}$,

The $\sigma_{\text {Det }, i j}$ depend on the efficiency with which one photon is counted by the detector and is defined as the square root of the signal. The $\sigma_{\mathrm{EC}, i j}$ were estimated at $0.01 \mathrm{keV}$ for SLS spectra (representing $\sim 2$ channels) and $0.02 \mathrm{keV}$ for HASYLAB spectra (representing $\sim 1$ channel). Gaussian probability distributions representing energy calibration biases (i.e. $\mathrm{keV}$ or energy offsets) are constructed using the above values as the standard deviation (SD). From these distributions, several offsets are selected, such that the perturbations are uniformly sampled according to probability, and the XRF spectra are refitted (here 20 offsets). The $\sigma_{\mathrm{EC}, i j}$ are defined as the $\mathrm{SD}$ of the refitted spectra across these 20 iterations. Entries in $x_{i j}$ with a signal-to-noise ratio (SNR) below 2 are downweighted by replacing the corresponding $\sigma_{i j}$ with $2 / \mathrm{SNR}_{i j}$. This approach, as opposed to downweighting an entire variable (i.e. increasing the uncertainty associated with an entire column rather than a single point; Paatero and Hopke, 2003), allows variables with low average SNR but high SNR periods to remain in the data matrix, as these peaks might contain valuable information regarding sources (e.g. sources systematically sampled from particular wind vectors).

Missing values in one or several entries in $x_{i}$ (e.g. a line fit failure of one or more elements) are set to zero and the corresponding error is set to $10^{9}$. Missing data points in time (e.g. a power failure during sampling) are removed from the data and error matrices.

\subsection{Selection of ME-2 solutions}

The multi-size, multi-site nature of this data set allowed for several methods of constructing the input data set for ME2 (i.e. single size $\times$ single site; single size $\times$ multiple sites; multiple sizes $\times$ single site; multiple sizes $\times$ multiple sites). Although all combinations were investigated, the analysis herein focuses primarily on the single size $\times$ multiple sites option. That is, we investigated three data sets, with each containing a single size $\left(\mathrm{PM}_{10-2.5}, \mathrm{PM}_{2.5-1.0}\right.$ or $\mathrm{PM}_{1.0-0.3}$ fraction) and data from all three measurement sites (MR, NK and DE). Combining the sites enabled separation of sources with high temporal covariance but significant spatial variability. Separation of sizes improved source resolution by preventing sources occurring in only a single size fraction from 
having too small a contribution to $Q$ for the model to resolve. Sources occurring only at one site were resolved, as discussed below.

ME-2 solutions were evaluated using a number of mathematical and physical criteria. The two major aspects of the analysis are (1) selection of the optimum number of factors and (2) evaluation of whether this solution is acceptable as a final solution or requires additional/modified rotational control. The primary criteria used for this evaluation are as follows:

\section{Mathematical}

- Investigation of the decrease in $Q / Q_{\exp }\left(Q_{\exp }=\right.$ $Q_{\text {expected }}$ or the number of remaining degrees of freedom of the system) with increasing $p$ (number of factors) due to the increased degrees of freedom in the model (Paatero and Tapper, 1993). A large decrease indicates significantly increased explanation of the data, while a small decrease suggests that additional factors are not providing new information and a smaller $p$ is sufficient.

- The element $e_{i j} / \sigma_{i j}$ (scaled residuals) are approximately normally distributed between approximately \pm 3 (Paatero and Hopke, 2003) and show comparable frequency distributions across sites.

Physical

- Attribution of elements to sources and element-toelement ratios within a source are consistent with existing measurements (e.g. published source profiles and source-based element-to-element ratios).

- Sources retrieved in several size fractions show reasonable consistent attribution of elements with co-varying time series.

- Sources show meaningful diurnal variations and concentration gradients from kerbside to urban background to rural sites (local: strong variations and large gradients; regional: flat diurnal patterns and minimal gradients).

- Correlations of factor time series with external tracers (e.g. traffic with $\mathrm{NO}_{x}$ ) are logical.

The goal of the present analysis is to conduct ME-2 analyses (unconstrained or constrained) that meet the criteria outlined above for each of the three size fractions on the combined data from all three sites. However, for all size fractions, unconstrained ME-2 (i.e. uncontrolled rotations or conventional PMF) yielded factors containing signatures of multiple emission sources (e.g. mixed brake wear and other traffic-related processes, or mixed S-rich and solid fuel) and were therefore considered non-optimal solutions (Supplement Figs. S1-S4). Therefore, we applied rotational controls, using the $a$ value approach (Eq. 3). A central challenge of this approach is the construction of appropriate anchor profiles, which cannot be drawn directly from the literature, because the attribution of elements to sources and the element-to-element ratios within a source are not consistent across different studies (e.g. Viana et al., 2008). Therefore, to find clean model rotations, anchor profiles were determined within the ME-2 analysis as described below.

In brief, this analysis strategy (outlined in Fig. 2, and illustrated for the current study in Supplement Fig. S5) involves the construction of a basis set of source profiles by iterating between (1) analysis of a subset of data in which one or more factors can be clearly resolved and their profiles added to the basis set and (2) analysis of the full data set using the existing basis set as anchors to determine whether the existing basis set is sufficient or additional anchor profiles are needed. Finally, sensitivity tests are used to assess the uncertainties associated with the final solution. Implementation of this analysis strategy requires four types of ME-2 analyses, denoted ME2_all, ME2_subset, Profile_unresolved, and Sensitivity_test, which are discussed in detail below.

ME2_all refers to the analysis of the entire data set (i.e. all time points). The initial ME2_all analysis in Fig. 2 is an unconstrained analysis and is primarily used to identify time segments that may be useful for resolving anchor profiles of specific factors. All subsequent ME2_all analyses utilize the profile basis set built up in previous steps by constraining successfully retrieved profiles during these steps. An ME2_all analysis is defined as successful only when the entire data set is well explained according to the criteria given above.

ME2_subset denotes analysis of a subset of the full data set in the rows $(i)$ dimension. This subset need not be a single continuous block and can be constructed, for example, from separate periods in which a particular source is evident. ME2_subset analyses utilize the basis set built up in previous steps and are considered successful (see Fig. 2) if the entire subset is well explained according to the above criteria. To maximize adaptation of the basis set to the entire data set (rather than remaining fixed to a previously analysed and quasi-arbitrary subset), the basis set is allowed to evolve after each successful ME2_subset (or ME2_all) analysis - i.e. the ME2_subset output profiles become the new basis set. Strategies used for selecting subsets may vary with the data set; however, it is critical that the entire data set be well investigated, by ensuring that the entire data set is contained in subsets and/or careful inspection of ME2_all residuals. As an example, in the present analysis high signal-tonoise data at MR and NK were analysed separately (subset 1) from low signal-to-noise data at DE (subset 2). The need for a separate DE analysis was indicated by strong residuals in the ME2_all analysis using the basis set derived from subset 1. This indicated that an additional source (industrial) was 


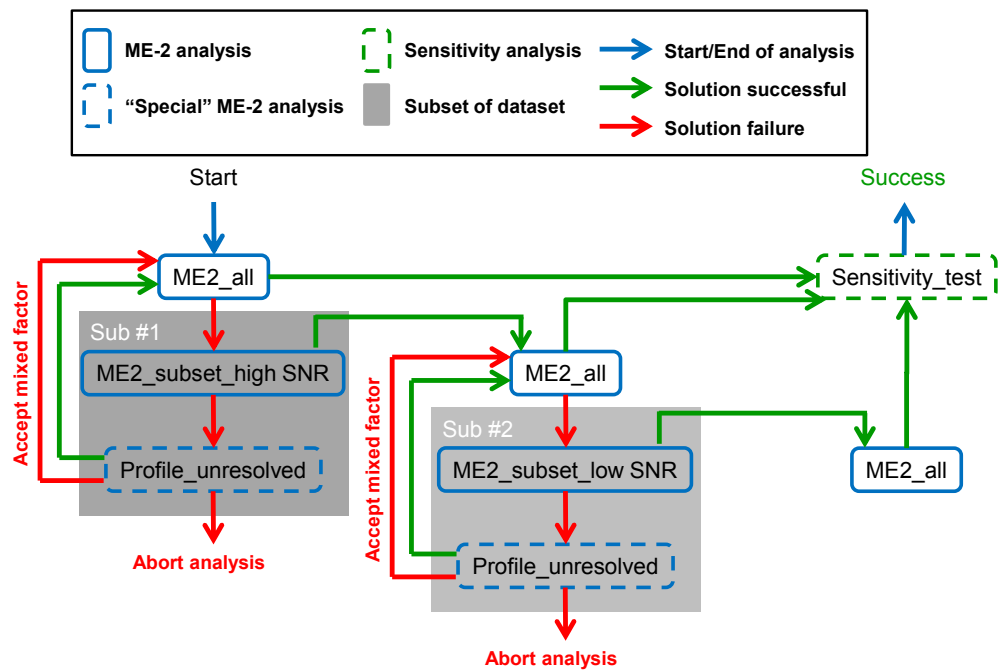

Figure 2. Schematic representation of the ME-2 analysis strategy. Four types of ME-2 analyses are represented: (1) ME-2 on entire data set (ME2_all), (2) ME-2 on a subset of data (ME2_subset, e.g. by high and low SNR), (3) profile determination or estimation of factors unresolvable by ME2_all or ME2_subset (PROF_unresolved), and (4) sensitivity tests to quantify rotational model uncertainties (Sensitivity_test). For simplicity, we show a case where analysis of two subsets of the data set is sufficient to construct the source profile basis set but where in theory $n$ segments can be used. See Supplement Fig. S5 for application to data sets used in this study.

needed to fully describe the data set. Other subset selection strategies could include, for example, size fraction, air mass origin, wind direction, or suspected source influence.

Profile_unresolved is used to generate an appropriate anchor profile for a factor whose presence is indicated in the solution but cannot be cleanly resolved by ME2_subset. Thus while Profile_unresolved and ME2_subset may employ similar analytical strategies (e.g. analysis of a data subset), Profile_unresolved is distinguished in that (1) success/failure criteria are applied only with respect to a specific factor and that (2) only the profile of this specific factor is added to the basis set for future analyses. As an example, in the present study, a profile for the $\mathrm{PM}_{10-2.5}$ brake wear factor was resolved by analysing NK data using an excessive number of factors. Although non-brake wear factors exhibited non-interpretable mixing/splitting, the brake wear factor was judged clean based on element ratios consistent with literature, a strong temporal correlation with $\mathrm{NO}_{x}$, and low overall unexplained variation in the solution. Other Profile_unresolved methods could include, for example, (1) an average profile over periods where the source of interest dominates the total signal or (2) use or estimation of a profile from the literature.

Sensitivity_test investigates the uncertainties in the ME-2 solution associated with the final basis set (fully constrained ME2_all). The robustness or uncertainty is investigated with anchor sensitivity analyses for each size fraction separately (three sites combined per size). Random profiles of all source profiles in ME2_all are generated over 10000 runs by varying the relative intensity of $f_{k j}$ with an anchor of $\pm 20 \%$ of the final model solutions. This allowed a systematic explo- ration of a large area of the solution space around the final solutions. Physically and mathematically meaningful solutions were selected according to the source profile constraints given in Table 1. By obeying these constraints in this study, one assures that the other source profiles are meaningful solutions as well. In the coarse fraction, $26 \%$ of the runs were classified as good solutions, while 40 and $64 \%$ are good in intermediate and fine fractions. Factor profile and time series uncertainties are defined as $1 \mathrm{SD}$ of the good solutions (note that these uncertainties are rather small (see, for example, small shaded areas in time series in Figs. 4, 5, 7$12,14)$ and an implication of the criteria in Table 1 , even though these criteria are not strongly restrictive). An anchor of $\pm 50 \%$ led to a higher percentage of meaningless solutions, while the uncertainties were comparable to the $\pm 20 \%$ anchor runs. This indicates that the rotational model uncertainties are rather driven by the criteria in Table 1 than by how much the profiles are allowed to vary. In other words, the percentage of accepted solutions reflects computational efficiency rather than the robustness of the base solution. The brake wear profile constraint ensures a clean factor without mixing of elements related to other traffic processes or resuspended dust that occurs due to the dominant contribution of MR to $Q$ with its high temporal covariance of most elements. The constraints based on literature values guarantee solutions that have environmentally meaningful attributions of elements to sources and element-to-element ratios within a source. Note that the errors reported for this analysis deal explicitly with model errors and do not account for systematic errors in the RDI-SR-XRF system that do not affect the PMF model operation (e.g. flow rate, element calibrations). 
Table 1. Source profile constraints.

\begin{tabular}{lll}
\hline & Criteria & Constraints \\
\hline $\mathrm{PM}_{10-2.5}$ & Relative intensity in brake wear factor of & \\
& $\mathrm{Cu}+\mathrm{Zn}+\mathrm{Zr}+\mathrm{Mo}+\mathrm{Sn}+\mathrm{Sb}+\mathrm{Ba}$ & $>75 \%$ \\
& $\mathrm{Al} / \mathrm{Si}$ in resuspended dust factor & $\pm 40 \%$ of $0.3^{\mathrm{a}}$ \\
& $\mathrm{Mg} / \mathrm{Na}$ in aged sea salt factor & $\pm 40 \%$ of $0.12^{\mathrm{b}}$ \\
$\mathrm{PM}_{2.5-1.0}$ & $\mathrm{Relative} \mathrm{intensity} \mathrm{in} \mathrm{brake} \mathrm{wear} \mathrm{factor} \mathrm{of}$ & $>70 \%$ \\
& $\mathrm{Cu}+\mathrm{Zn}+\mathrm{Zr}+\mathrm{Mo}+\mathrm{Sn}+\mathrm{Sb}+\mathrm{Ba}$ & $\pm 40 \%$ of $0.3^{\mathrm{a}}$ \\
& $\mathrm{Al} / \mathrm{Si}$ in resuspended dust factor & $\pm 40 \%$ of $0.12^{\mathrm{b}}$ \\
& $\mathrm{Mg} / \mathrm{Na}$ in aged sea salt factor & $\mathrm{Cl} / \mathrm{Na} \pm 20 \%$ of avg. \\
$\mathrm{PM}_{1.0-0.3}$ & $\mathrm{Avg} . \mathrm{Cl} / \mathrm{Na}$ in mean good solutions of $\mathrm{PM}_{10-2.5}$ & $\leq 10 \%$ of min. $Q / Q_{\exp }^{\mathrm{c}}$ \\
& and $\mathrm{PM}$ \\
\hline
\end{tabular}

a Rudnick and Gao (2003), also used, for example, by Cuccia et al. (2010). ${ }^{\text {b }}$ Average sea water composition (Seinfeld and Pandis, 2006). ${ }^{\mathrm{c}}$ Minimum $Q / Q_{\text {exp }}$ of good solutions, after physical criteria are met.

For a detailed discussion of these sources of uncertainty, see Visser et al. (2015).

\section{Results and discussion}

\subsection{ME-2 source apportionment}

The ME-2 analysis on the three data sets resulted in a total of nine source profiles as shown in Fig. 3 (values in Supplement Tables S1-S3), with the factor time series for each site in Supplement Figs. S6-S8 ( $\mathrm{PM}_{10-2.5}, \mathrm{PM}_{2.5-1.0}$ and $\mathrm{PM}_{1.0-0.3}$, respectively). The coarse fraction yielded the source factors (notable elements in brackets) brake wear $(\mathrm{Cu}, \mathrm{Zr}, \mathrm{Sb}, \mathrm{Ba}$ ), other traffic-related $(\mathrm{Fe})$, resuspended dust $(\mathrm{Si}, \mathrm{Ca})$, sea/road salt $(\mathrm{Cl})$, aged sea salt $(\mathrm{Na}, \mathrm{Mg})$ and industrial $(\mathrm{Cr}, \mathrm{Ni})$. The intermediate fraction yielded the same factors except for the industrial, instead yielding an S-rich (S) factor. In the fine fraction a traffic-related $(\mathrm{Fe}, \mathrm{Cu}, \mathrm{Zr}, \mathrm{Sb}, \mathrm{Ba})$ factor was found as well as resuspended dust, sea/road salt, aged sea salt, reacted $\mathrm{Cl}(\mathrm{Cl})$, S-rich and solid fuel $(\mathrm{K}, \mathrm{Pb})$. The other elements (Al, P, Ti, V, Mn, Zn, Br, Sr, Mo, Sn) are not uniquely emitted by a particular emission source and are attributed to several factors. It should be noted that the concentrations for the factor time series reported below reflect only the elements measured by SR-XRF analysis and not the other constituents associated with the various source types. In particular the lighter elements $(\mathrm{H}, \mathrm{C}, \mathrm{N}, \mathrm{O})$ are not included and may in some cases dominate the total mass associated with a source. The relative contribution to the factors discussed herein are also relative to the measured elemental mass resolved. Although the analysis below includes only trace elements, which constitute a minor fraction of the total mass, the results are important for determining source temporal characteristics and interpreting trends in bulk particle properties such as total PM mass.

\subsubsection{Brake wear and other traffic-related}

Factors related to brake wear were resolved in $\mathrm{PM}_{10-2.5}$ and $\mathrm{PM}_{2.5-1.0}$ size fractions; the profiles are shown in Fig. 3, with time series and diurnal variations in Fig. 4. The relative contribution to this factor is more than $70 \%$ for $\mathrm{V}, \mathrm{Cu}, \mathrm{Zn}, \mathrm{Zr}$, $\mathrm{Sn}, \mathrm{Sb}$ and $\mathrm{Ba}$ in both size fractions, and more than $70 \%$ for $\mathrm{Cr}, \mathrm{Ni}, \mathrm{Sr}$ and Mo in $\mathrm{PM}_{2.5-1.0}$. Zn can be emitted both from brake and tyre wear, indicating that these factors might be a mixture of various wearing processes (Pant and Harrison, 2013). Factors for other traffic-related emissions in these two size fractions (Figs. 3 and 5) are dominated by Fe, with around $86 \%$ of the mass explained by this element. The finefraction analysis retrieved one traffic factor with a mixture of brake wear and other traffic-related emissions with $84 \%$ of the mass explained by $\mathrm{Fe}$ (relative contributions more than $70 \%$ for $\mathrm{Fe}, \mathrm{Cu}, \mathrm{Zr}, \mathrm{Sb}$ and $\mathrm{Ba}$ ). This mixed factor is similar to that reported by Amato et al. $(2009 \mathrm{~b}, 2013)$ and Bukowiecki et al. (2010) although the ratio of Fe to other elements is variable between studies. $\mathrm{V}$ and $\mathrm{Sr}$ are typically not attributed to traffic factors but rather to industrial or oil combustion emissions (V) and dust resuspension ( $\mathrm{Sr}$ ) (Minguillón et al., 2014; Moreno et al., 2011). However, both elements are found in trace amounts in fuel additives and brake lining, and Handler et al. (2008) showed enhanced Sr and V concentrations inside a tunnel compared with ambient concentrations outside. In the absence of other sources, the relative contribution of these elements might dominate these traffic factors.

For the brake wear and the $\mathrm{PM}_{1.0-0.3}$ traffic factors, the $\mathrm{Cu} / \mathrm{Sb}$ ratios of 6.3-7.1 fall within the range of 5.7-8.2 for previous measurements at MR and NK by Harrison et al. (2012b) and depend on brake pad compositions and contributions of metals from other sources (Pant and Harrison, 2013). The $\mathrm{Cu} / \mathrm{Ba}$ ratios of 1.1-1.4 are in good agreement with the median ratio of 1.2 obtained by Sturtz et al. (2014). 


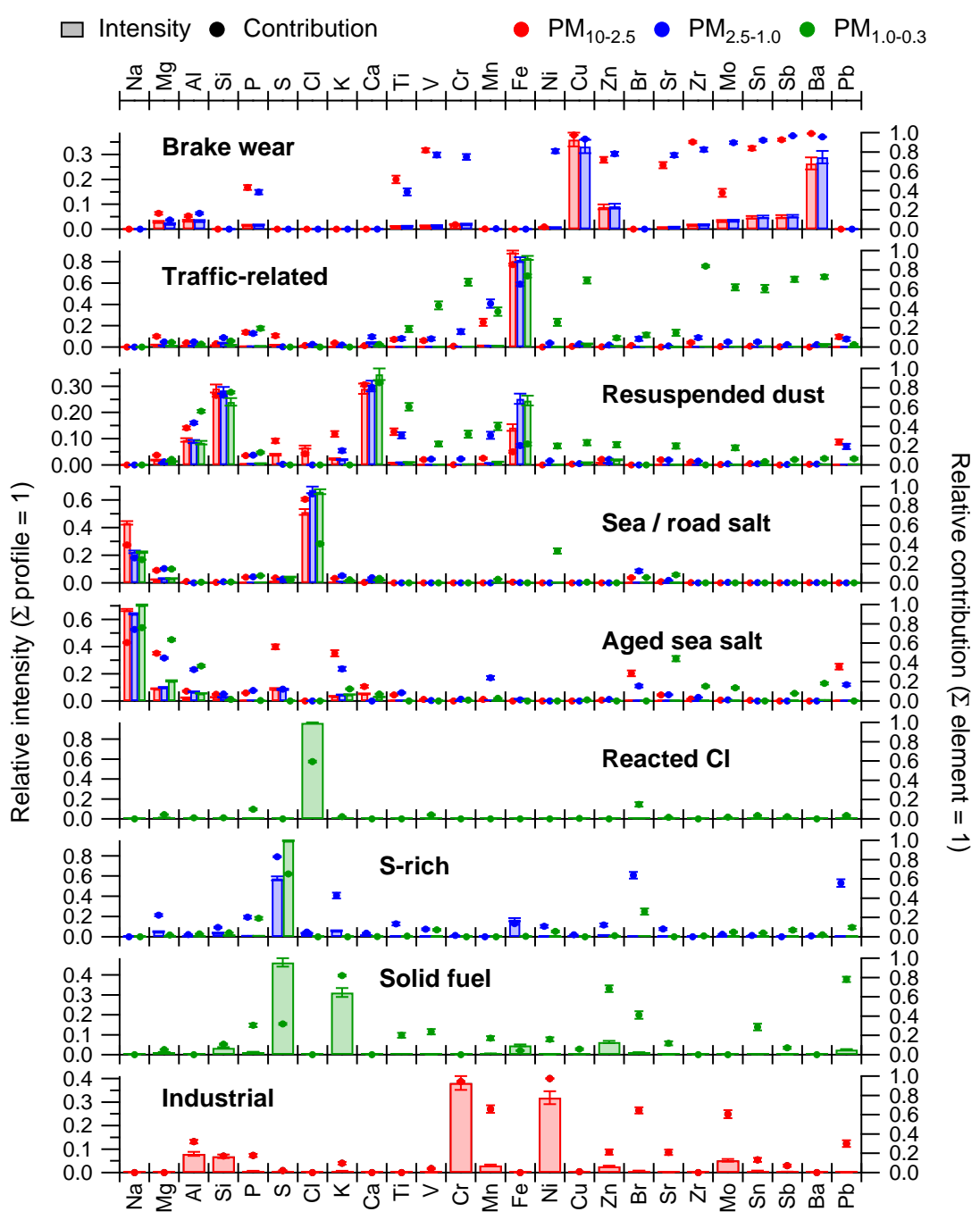

Figure 3. Source profiles of ME-2 results on combined data of the MR-NK-DE sites. The bars (left $y$ axis) represent the average element intensity to each factor in $\mathrm{ng} \mathrm{ng}^{-1}$; circles (right $y$ axis) represent the fraction of the total predicted concentration for a given element. Data are given as mean of good solutions \pm 1 SD from the anchor sensitivity analysis. Note that not all factors are retrieved in all size fractions. See Supplement Tables S1-S3 for the values.

All the traffic-related factors are strongly influenced by local traffic emissions with steep MR to NK to DE concentration gradients (Figs. 4-5). Concentrations at MR are 3.6-6.8 and 9.9-28 times higher than at NK and DE, respectively. The diurnal variations show a double maximum during the day corresponding to rush hours. Most of the mass is emitted in the coarse fraction, with concentrations at MR being 2.63.6 and 7.5 times higher than in $\mathrm{PM}_{2.5-1.0}$ and $\mathrm{PM}_{1.0-0.3}$, respectively. The time series correlate well across sizes (Pearson's $R$ 0.67-0.81), indicating similar emission processes. Both traffic sources are well correlated with $\mathrm{NO}_{x}$ across sites and sizes (Pearson's $R$ 0.53-0.72) as shown in Fig. 6 for MR (NK and DE in Supplement Fig. S9). Figure 6 also shows traffic flows at MR of light- (LDV) and heavy-duty vehicles (HDV) (vehicles $<5.2 \mathrm{~m}$ long, LDV; vehicles $>5.2 \mathrm{~m}$ long, $\mathrm{HDV}$ ). The diurnal variations are much stronger for $\mathrm{NO}_{x}$ and
HDV than for the traffic factors and LDV. The ratios between values at 08:00 and 02:00 UTC are about 4.1 for the former and 2.0 for the latter, probably caused by more strongly enhanced emissions between HDV and LDV for $\mathrm{NO}_{x}$ (factor of $\sim 37$ ) relative to brake wear (factor of $\sim 10$ ), as identified by Bukowiecki et al. (2010). $\mathrm{NO}_{x}$ seems therefore more directly related to HDV numbers, while the traffic factors are more influenced by total vehicle number.

\subsubsection{Resuspended dust}

Resuspended dust factors were resolved in all size fractions; the profiles are shown in Fig. 3, with time series and diurnal variations in Fig. 7. The source profiles are very similar across sizes and the mass is dominated by $\mathrm{Si}, \mathrm{Ca}$ and $\mathrm{Fe}$, consistent with the upper continental crust composition 

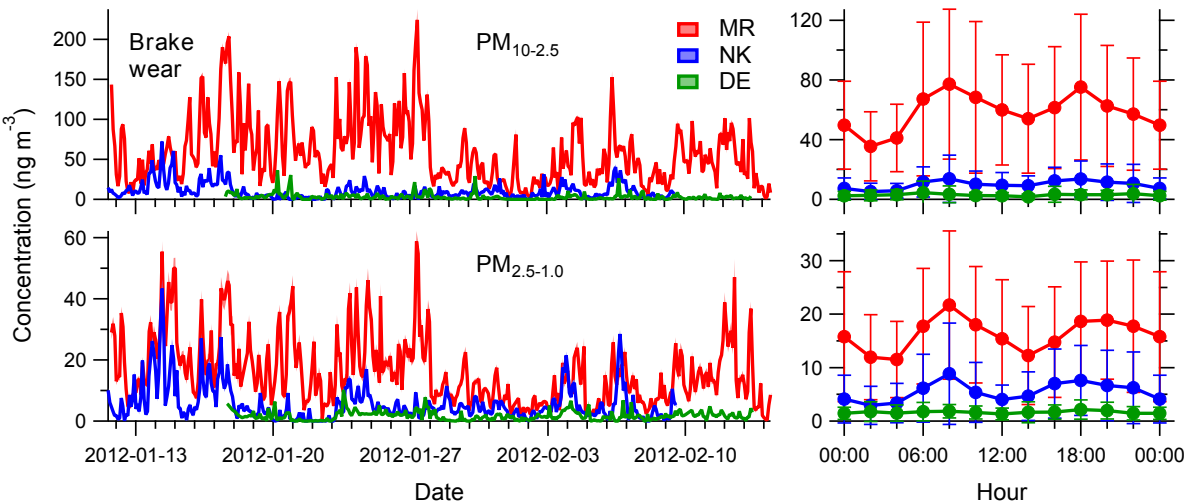

Figure 4. Time series (left) and diurnal variations (right) of the brake wear factor at MR, NK and DE for $\mathrm{PM}_{10-2.5}$ and $\mathrm{PM}_{2.5-1.0}$. Time series show the mean of all good solutions $\pm 1 \mathrm{SD}$ as shaded areas. Diurnals show the mean of the time series $\pm 1 \mathrm{SD}$ as whiskers, with the hour being the start of a $2 \mathrm{~h}$ sampling period (00:00 UTC means sampling from 00:00 to 02:00 UTC).
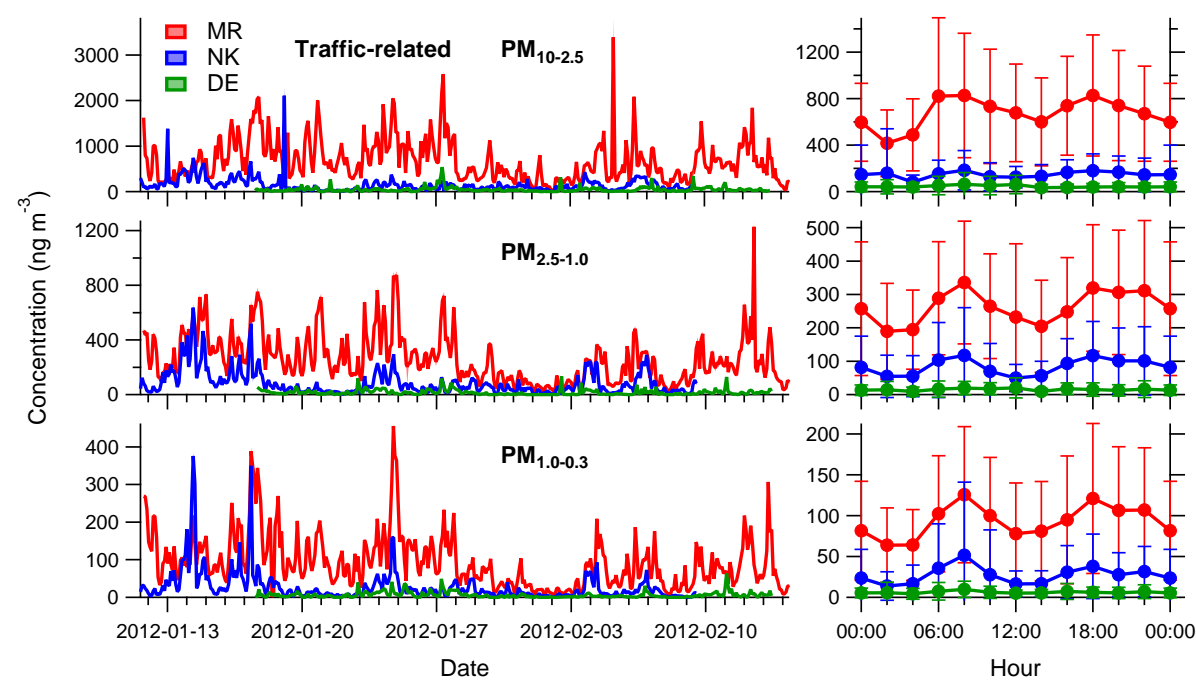

Figure 5. Time series (left) and diurnal variations (right) of the other traffic-related factor at $\mathrm{MR}, \mathrm{NK}$ and $\mathrm{DE}_{\text {for }} \mathrm{PM}_{10-2.5}, \mathrm{PM}_{2.5-1.0}$ and $\mathrm{PM}_{1.0-0.3}$. Time series show the mean of all good solutions $\pm 1 \mathrm{SD}$ as shaded areas. Diurnals show the mean of the time series \pm 1 SD as whiskers, with the hour being the start of a $2 \mathrm{~h}$ sampling period (00:00 UTC means sampling from 00:00 to 02:00 UTC).

(Rudnick and Gao, 2003) and previous source apportionment studies (Amato et al., 2009a; Dall'Osto et al., 2013; Richard et al., 2011).

The scaled residuals $\left(e_{i j} / \sigma_{i j}\right)$ ratios exceed \pm 3 for $\mathrm{Na}$, $\mathrm{Si}$ and $\mathrm{Ca}$ (coarse); $\mathrm{Na}, \mathrm{Al}, \mathrm{Si}$ and $\mathrm{Ca}$ (intermediate); and $\mathrm{Al}$ and $\mathrm{Si}$ (fine) and/or are skewed at the sites relative to each other. This spread in the scaled residuals for these dustrelated elements may indicate different dust profiles across sites, especially at DE relative to the city sites. This is potentially caused by varying dust compositions or emission processes. Resuspension in the city is dominated by road dust influenced by anthropogenic activities and by other dustgenerating activities, such as construction works, in contrast to influences from natural soils at DE. This is in line with Sturtz et al. (2014), where city-specific soil profiles are constrained in the ME-2 analysis on data of combined cities, and with Amato et al. (2009a), where ME-2 yielded a road dust resuspension distinct from a mineral dust factor. In the current study, increasing $p$ yielded factors with high relative intensities of $\mathrm{Ca}$ and of $\mathrm{Al}$ and $\mathrm{Si}$. However, $Q / Q_{\exp }$ and structures in $e_{i j} / \sigma_{i j}$ remain unaffected, indicating that temporal co-variance and emission source strengths of these elements are too similar across sites for the model to retrieve more than one dust factor.

Similar to the factor termed "traffic-related", dust is mainly emitted in $\mathrm{PM}_{10-2.5}$ with up to 13.6 times higher concentrations than in the smaller fractions. The factor time series (Fig. 7) indicate enrichment at MR relative to NK and $\mathrm{DE}$, especially for the coarse fraction (MR / NK ratio of 3.4 and MR / DE of 7.8) and are well correlated among all sizes (Pearson's $R$ 0.62-0.78). The diurnal variations show strong daytime maxima, most likely from anthropogenic 

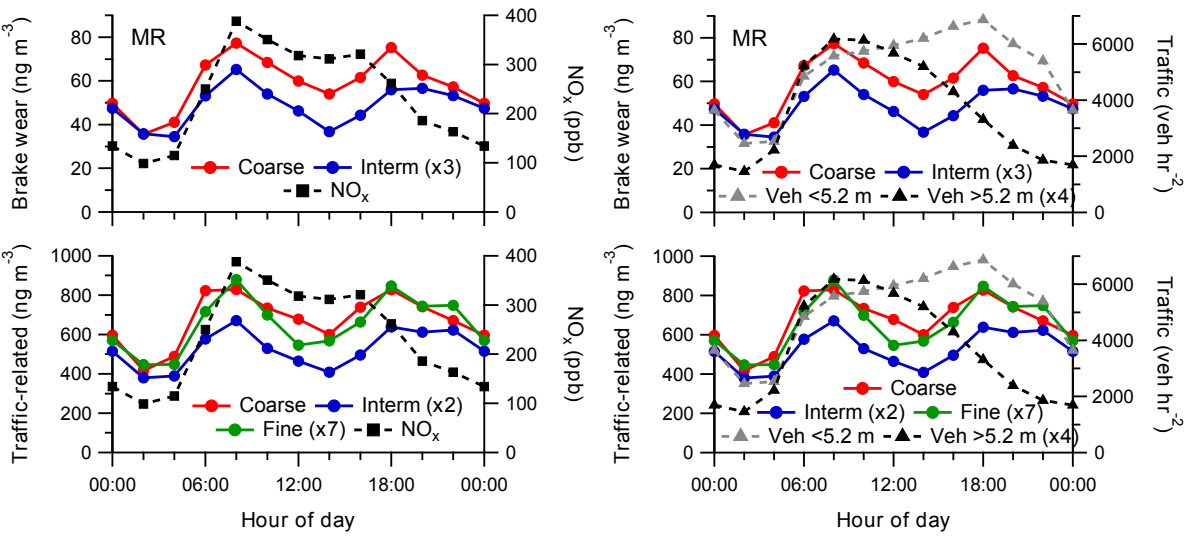

Figure 6. Diurnal variations in the brake wear $\left(\mathrm{PM}_{10-2.5}\right.$ - coarse, $\mathrm{PM}_{2.5-1.0}$ - intermediate) and other traffic-related (coarse, intermediate, $\mathrm{PM}_{1.0-0.3}$ - fine) factors at MR compared to diurnal variations of $\mathrm{NO}_{x}$ (left) and traffic flow (right). Hour of day is start of a $2 \mathrm{~h}$ sampling period (00:00 UTC means sampling from 00:00 to 02:00 UTC). Note the scaling applied to several tracers.

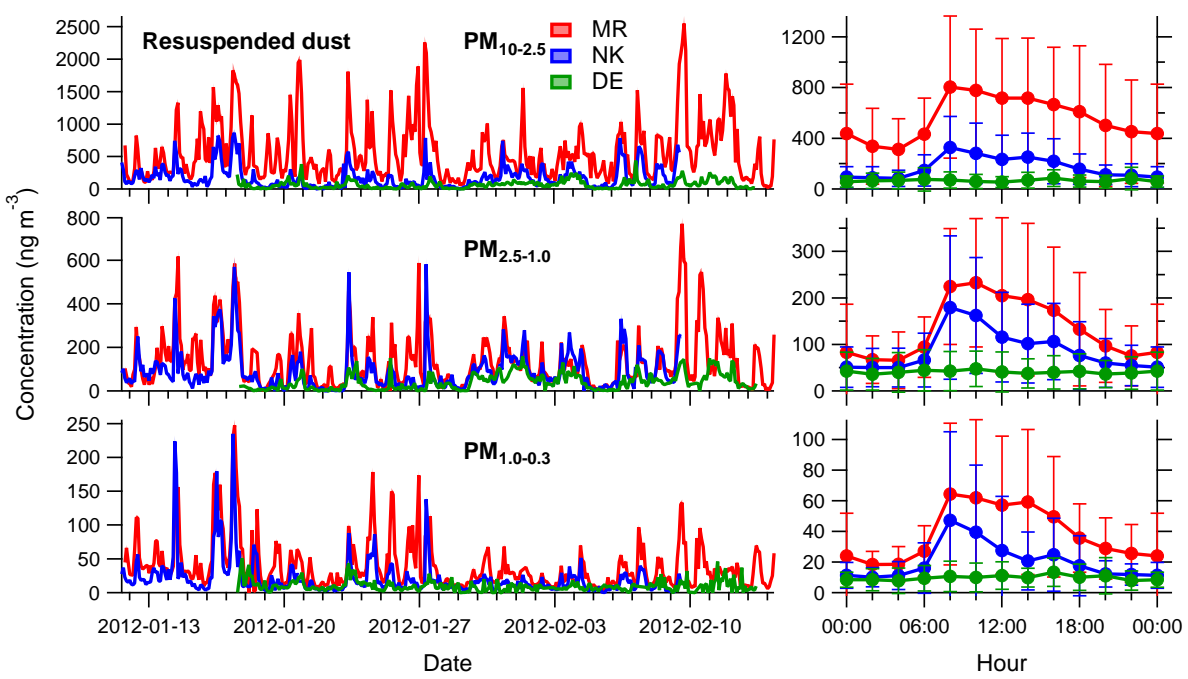

Figure 7. Time series (left) and diurnal variations (right) of the resuspended dust factor at $\mathrm{MR}, \mathrm{NK}$ and $\mathrm{DE}_{\text {for }} \mathrm{PM}_{10-2.5}, \mathrm{PM}_{2.5-1.0}$ and $\mathrm{PM}_{1.0-0.3}$. Time series show the mean of all good solutions $\pm 1 \mathrm{SD}$ as shaded areas. Diurnals show the mean of the time series \pm 1 SD as whiskers, with the hour being the start of a $2 \mathrm{~h}$ sampling period (00:00 UTC means sampling from 00:00 to 02:00 UTC).

activities (mainly traffic) throughout the day. The increase at 08:00 UTC (sampling 08:00-10:00 UTC) occurs $2 \mathrm{~h}$ after increasing traffic numbers, $\mathrm{NO}_{x}$ and traffic-related source emissions (Fig. 6). The delay is probably caused by a combination of two effects. On the one hand, the RH still increases during morning hours, resulting in wetter road surfaces than later in the day (Supplement Fig. S10). On the other hand, increasing traffic flows induce increased wind movements in the street canyon, resulting in enhanced particle resuspension (Bukowiecki et al., 2009).

\subsubsection{Sea/road salt, aged sea salt and reacted Cl}

Sea/road salt and aged sea salt were resolved in all sizes; Fig. 3 shows the profiles, with time series and diurnal variations in Figs. 8-9. The mass of sea/road salt comes almost exclusively from $\mathrm{Na}$ and $\mathrm{Cl}$, whereas aged sea salt is largely driven by $\mathrm{Na}$. The crustal component of $\mathrm{Na}$ is less than $1 \%$ in this study, based on the $\mathrm{Na} / \mathrm{Si}$ ratio found in the upper continental crust (Wedepohl, 1995). Therefore, the combination of $\mathrm{Na}$ with relative contributions of more than $50 \%$ for coarse $\mathrm{Mg}, \mathrm{S}$ and $\mathrm{K}$, but depleted $\mathrm{Cl}$ supports aged particles with a sea salt origin, in which the $\mathrm{Na}$ is neutralized by compounds not resolved by our analysis (e.g. nitrate). The $\mathrm{Mg} / \mathrm{Na}$ mass ratio of the sea/road salt factor is only 0.054 in $\mathrm{PM}_{10-2.5}$ (theoretical sea salt ratio is 0.12; Seinfeld and Pandis, 2006). De-icing salt was applied on the roads in London during the measurement campaign, and this salt is typically composed of coarse $\mathrm{NaCl}$, resulting in enriched coarse $\mathrm{Na}$ relative to $\mathrm{Mg}$ concentrations after the particles are resuspended in the air. The low concentrations of fine sea salt 
are in line with Mazzei et al. (2007), since sea salt is mainly emitted as particles with $d>1.0 \mu \mathrm{m}$.

The data suggest that a fraction of the aged sea salt is directly transported from the sea, while part comes from resuspended sea salt particles after deposition on roads. Direct transport is indicated by the diurnal variations (Figs. 8-9), which have no obvious pattern - peaks occur at different hours of the day throughout the entire time series, whereas resuspension would likely peak during the day with vehicle use. Additional support is provided by NAME dispersion modelling and wind direction analyses, which indicate that high concentration episodes in the aged sea salt factor coincide with air masses from the sea. The sea salt concentrations also increase with increasing wind speed, consistent with other Na observations in the UK (Supplement Fig. S11; Twigg et al., 2015). However, the $\mathrm{PM}_{10-2.5}$ concentrations of the aged sea salt factor are enhanced by a factor of 1.3 and 2.2 at the kerbside (MR) site relative to the urban background (NK) and rural (DE) sites, respectively. This suggests that aged sea salt concentrations are also significantly modulated by human activity in the form of resuspension.

Reacted $\mathrm{Cl}$ is unique to $\mathrm{PM}_{1.0-0.3}$ (profile in Fig. 3) and is mainly driven by an event at MR and NK lasting from 16:00 UTC on 5 February to 04:00 UTC on 7 February 2012 (time series and diurnal variations in Fig. 10; around 12 February concentrations at MR are high as well, but SR-XRF data at NK and meteorological data at BT Tower are absent during this period, making it impossible to study this episode in detail). Stagnant conditions prevailed in the city with low average wind speed of $2.1 \mathrm{~m} \mathrm{~s}^{-1}$ at about 190 ma.g.l. (data from BT Tower). The NAME $24 \mathrm{~h}$ backwards footprints show that the air sampled at MR and NK was dominated by local London air. In contrast, during this episode the air mass at DE is dominated by a mixture of London air and air from the southern UK. Although fine $\mathrm{Cl}$ can be emitted by combustion sources such as waste incineration (Moffet et al., 2008) and coal combustion (Yao et al., 2002), this factor does not correlate with combustion-related species such as $\mathrm{K}, \mathrm{Zn}, \mathrm{Pb}$ and $\mathrm{SO}_{2}$. The event discussed above does correlate with a strong peak in coarse-mode aged sea salt (Figs. 9-10). Sea salt particles in all size fractions have likely reacted with nitric acid $\left(\mathrm{HNO}_{3}\right)$, forming hydrochloric acid $(\mathrm{HCl})$. Due to stagnant conditions, follow-up reactions between $\mathrm{HCl}$ and ammonia $\left(\mathrm{NH}_{3}\right)$ could have taken place, forming ammonium chloride $\left(\mathrm{NH}_{4} \mathrm{Cl}\right)$. These particles occur mainly in the fine mode due to the highest surface-tovolume ratios. $\mathrm{NO}_{3}^{-}$and $\mathrm{NH}_{3}$ concentrations were high during this event, favouring such reactions. AMS measurements also show this unique $\mathrm{Cl}^{-}$episode at $\mathrm{MR}$ and $\mathrm{NK}\left(\mathrm{Cl}^{-}\right.$is negligible during the rest of the IOP and at DE). For this specific period the AMS aerosol charge balance in the city holds when $\mathrm{Cl}^{-}$is included, while this ion is not needed at $\mathrm{DE}$ or during the rest of the time to balance $\mathrm{NH}_{4}^{+}$within the uncertainties of the measurements, indicating the presence of fine $\mathrm{NH}_{4} \mathrm{Cl}$ particles.

\subsubsection{S-rich and solid fuel}

The S-rich factor, mainly composed of S, was resolved in $\mathrm{PM}_{1.0-0.3}$; the profile is shown in Fig. 3, with time series and diurnal variations in Fig. 11. This factor likely corresponds to secondary sulfates, consistent with the results of many previous source apportionment studies (Mazzei et al., 2007; Richard et al., 2011; Viana et al., 2007). All sites show similar concentrations without any patterns visible in the diurnal variations, consistent with regional sources. This factor correlates well with $\mathrm{AMS} \mathrm{SO}_{4}^{2-}$ measurements (Pearson's $R$ $0.61-0.86)$ and is elevated with air masses from the European mainland, mainly occurring during the second half of the campaign (Supplement Fig. S12).

The solid fuel factor was also resolved in the fine fraction (profile in Fig. 3, time series and diurnal variations in Fig. 12). The mass of this factor is dominated by $\mathrm{S}$ and $\mathrm{K}$, while the relative contributions to this factor are more than $60 \%$ for $\mathrm{K}, \mathrm{Zn}$ and $\mathrm{Pb}$. Surprisingly, the time series are very similar at all sites and are likely influenced by relatively fresh emissions from many point sources surrounding the measurement stations, including wood, coal and peat emissions in varying contributions (Harrison et al., 2012a; Young et al., $2015 b)$. The $\mathrm{S} / \mathrm{K}$ ratio of 1.5 is well within the observed range of $0.5-8$ for fresh to transported and aged emissions (Bukowiecki et al., 2010; Richard et al., 2011; Viana et al., 2013). The solid fuel source is compared to particle light absorption data by Aethalometer measurements $\left(b_{\mathrm{abs}, \mathrm{wb}}\right.$ in $\mathrm{m}^{-1}$; not available at MR) and solid fuel factors resolved by AMS-PMF on organic aerosol data (Detournay et al., 2015; Young et al., 2015a, b). The time series of the various solid fuel tracers are very similar, especially for the lightabsorbing particles and organic aerosol as shown for NK and DE in Fig. 13 (tracers at MR are similar to NK). The different correlations seen in this figure are caused by the sampling of air containing various burning stages of solid fuel burning, emitting $\mathrm{K}$ and other species in different ratios.

In the intermediate fraction S contributes around $58 \%$ to the mass of the S-rich factor (profile in Fig. 3, time series and diurnal variations in Fig. 11) and the relative contributions of $\mathrm{S}, \mathrm{Br}$ and $\mathrm{Pb}$ are $>50 \%$ in this factor. Mazzei et al. (2007) showed that $S$ is predominantly found in $\mathrm{PM}_{1}$, but particles of up to several micron were identified to contain $S$ as well. The intermediate $S$-rich factor contains signatures of both fine-fraction S-rich and solid fuel with similar concentrations at all sites and no obvious diurnal patterns.

\subsubsection{Industrial}

Constrained ME-2 analysis in the $\mathrm{PM}_{10-2.5}$ fraction on data across sites revealed large residuals with clear structures at $\mathrm{DE}$ for $\mathrm{Cr}, \mathrm{Ni}$ and $\mathrm{Mo}$, indicating that the data at the rural site were not fully explained. The "ME2_seg_low_SNR" analysis on DE PM $10-2.5$ (see Fig. 2 and Supplement Fig. S5) 


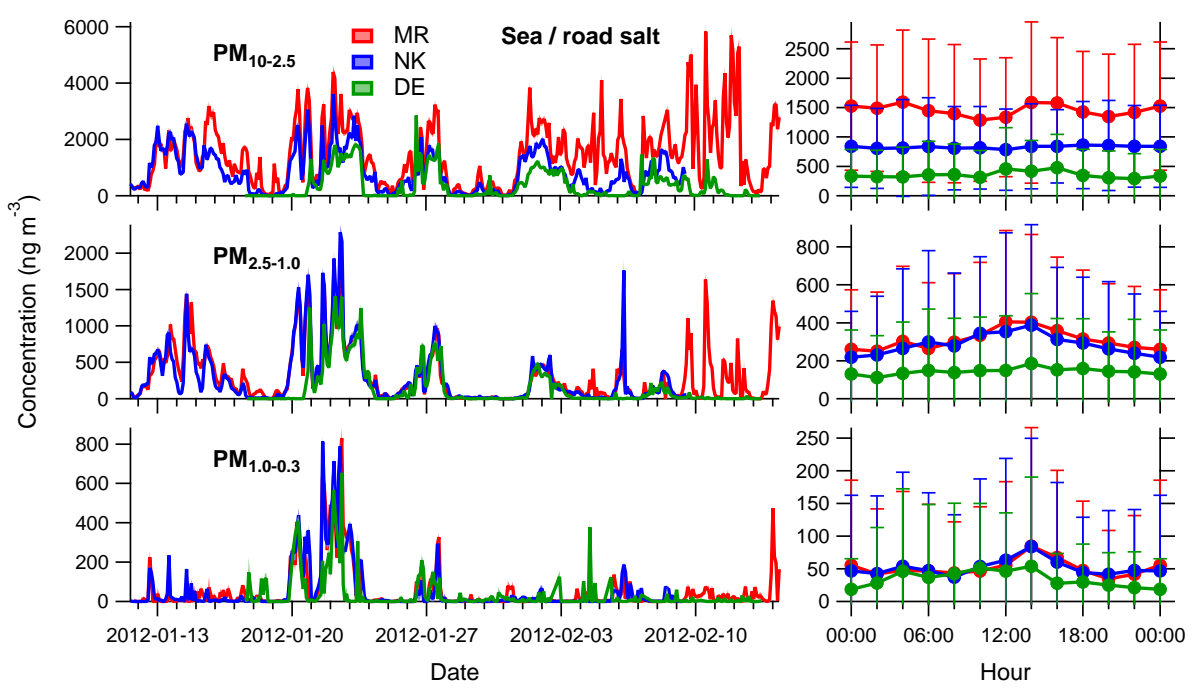

Figure 8. Time series (left) and diurnal variations (right) of the sea/road salt factor at $\mathrm{MR}, \mathrm{NK}$ and $\mathrm{DE}_{\text {for }} \mathrm{PM}_{10-2.5}, \mathrm{PM}_{2.5-1.0}$ and $\mathrm{PM}_{1.0-0.3}$. Time series show the mean of all good solutions $\pm 1 \mathrm{SD}$ as shaded areas. Diurnals show the mean of the time series \pm 1 SD as whiskers, with the hour being the start of a $2 \mathrm{~h}$ sampling period (00:00 UTC means sampling from 00:00 to 02:00 UTC).

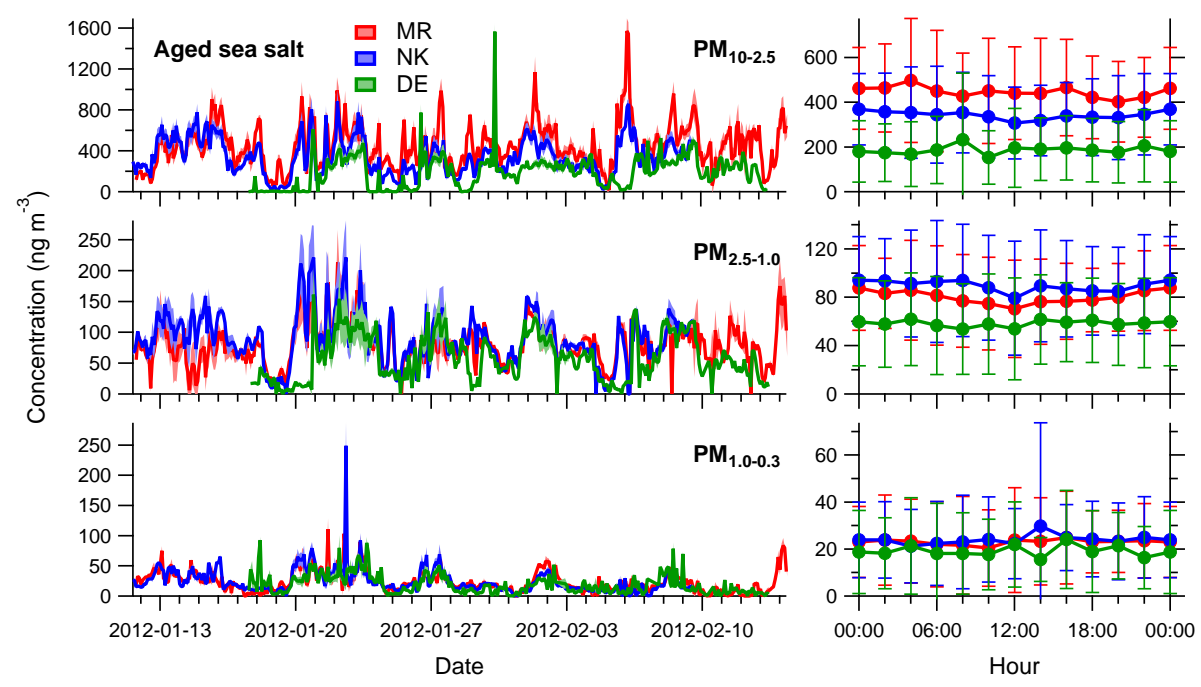

Figure 9. Time series (left) and diurnal variations (right) of the aged sea salt factor at $\mathrm{MR}$, NK and $\mathrm{DE}_{\text {for }} \mathrm{PM}_{10-2.5}, \mathrm{PM}_{2.5-1.0}$ and $\mathrm{PM}_{1.0-0.3}$. Time series show the mean of all good solutions $\pm 1 \mathrm{SD}$ as shaded areas. Diurnals show the mean of the time series $\pm 1 \mathrm{SD}$ as whiskers, with the hour being the start of a $2 \mathrm{~h}$ sampling period (00:00 UTC means sampling from 00:00 to 02:00 UTC).

successfully yielded a factor, potentially industrial, containing mainly these three elements without significant residuals.

Figure 3 shows the source profile and Fig. 14 the time series and diurnal variations. This source is mainly found at $\mathrm{DE}$ and consists of $70 \%$ of $\mathrm{Cr}$ and $\mathrm{Ni}$. The time series at MR and NK show only a few single peaks and can therefore not be attributed to this particular source. The spiky time series at $\mathrm{DE}$ are typical indications for influences of one or several point sources close to this rural site. These sources are possibly found in the southwest as concentrations were elevated under these conditions (Supplement Fig. S13). The towns of Detling and Maidstone are located towards the southwest of the Kent Showgrounds. Walterson (1998) studied Cr, Ni and Mo in Sweden and found that road traffic including road wear is the largest emitter of these elements, followed by industries, incineration, agriculture and waste water treatment. DeWees et al. (1992) identified $\mathrm{Pb}, \mathrm{Ni}$ and $\mathrm{Cr}$ in emissions from municipal wastewater sludge incinerators. Except for agricultural fields, none of those activities likely contribute to the emission source at DE. Probably some local activities at the Kent Showgrounds or small-scale industry in Maidstone like stainless steel production (Querol et al., 2007; Witt et al., 2010) contributes to this factor. 

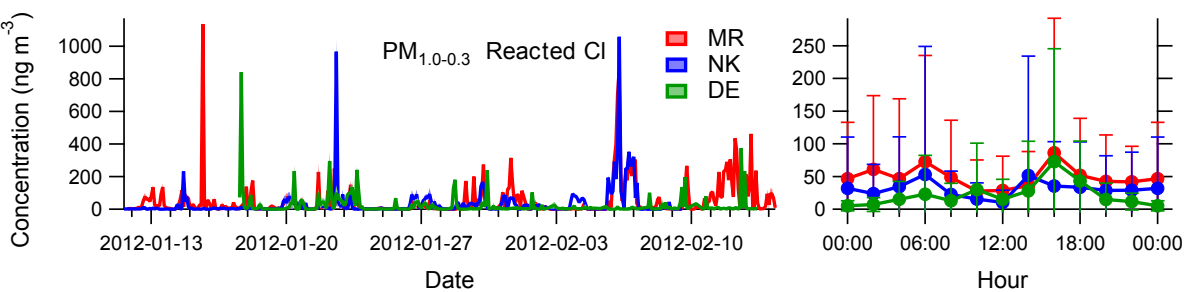

Figure 10. Time series (left) and diurnal variations (right) of the reacted $\mathrm{Cl}$ factor at MR, NK and DE for PM $1.0-0.3$. Time series show the mean of all good solutions $\pm 1 \mathrm{SD}$ as shaded areas. Diurnals show the mean of the time series $\pm 1 \mathrm{SD}$ as whiskers, with the hour being the start of a $2 \mathrm{~h}$ sampling period (00:00 UTC means sampling from 00:00 to 02:00 UTC).
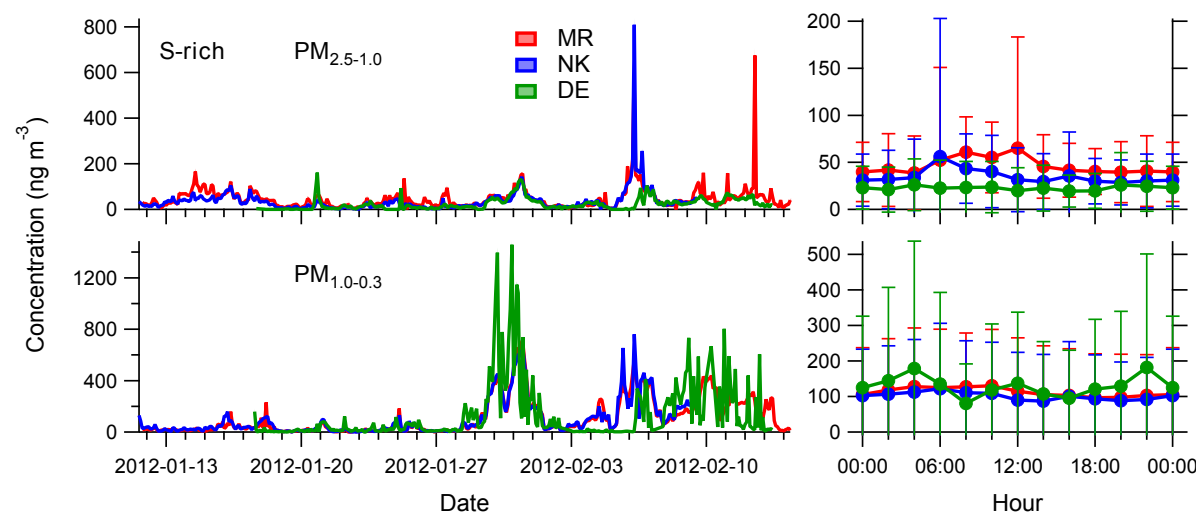

Figure 11. Time series (left) and diurnal variations (right) of the S-rich factor at MR, NK and DE for $\mathrm{PM}_{2.5-1.0}$ and $\mathrm{PM}_{1.0-0.3}$. Time series show the mean of all good solutions $\pm 1 \mathrm{SD}$ as shaded areas. Diurnals show the mean of the time series \pm 1 SD as whiskers, with the hour being the start of a $2 \mathrm{~h}$ sampling period (00:00 UTC means sampling from 00:00 to 02:00 UTC).

\subsection{Synthesis}

The trace element source apportionment results indicate the ability to characterize the environment-dependent variability of emissions in and around London. The analyses of data from the combined sites retrieve a single source profile representative of all three sites, thus allowing a direct comparison of the source strengths across sites. Source strengths strongly differ between sites and sizes, as seen in Fig. 15. Most of the analysed element mass is emitted in $\mathrm{PM}_{10-2.5}$ with $78 \%$ at MR, $73 \%$ at NK and $65 \%$ at DE, while only $17-22 \%$ and 6-13\% is emitted in $\mathrm{PM}_{2.5-1.0}$ and $\mathrm{PM}_{1.0-0.3}$, respectively.

The separate analyses on the three size fractions provide insights into the emissions of sources to specific size fractions (Fig. 15). The regionally influenced S-rich and solid fuel factors are restricted to the smaller size fractions with concentration ratios of 1.0-1.8 between sites roughly $50 \mathrm{~km}$ apart. These factors, especially solid fuel, are affected by many anthropogenic point sources and are influenced by emissions not only in and around London but also from elsewhere in the UK and northern Europe. In contrast to other sources, solid fuel is expected to be more prevalent in more rural parts of the UK than in the smoke-controlled inner city areas. The industrial factor is restricted to $\mathrm{PM}_{10-2.5}$ and affects the air quality under specific meteorological conditions around the rural site, which is generally a region characterized by much lower pollution.

The other sources, except reacted $\mathrm{Cl}$, emit elements in all three size fractions. London's city centre is a hotspot of anthropogenic activities, resulting in high pollution levels of locally influenced sources directly related to population density. Brake wear, other traffic-related and resuspended dust factor concentrations are drastically different within different micro-environments and size fractions, indicating major heterogeneity in human exposure patterns. Concentrations at the kerbside are up to 7 and 28 times higher than at NK and $\mathrm{DE}$, respectively, and $\mathrm{PM}_{10-2.5}$ concentrations are up to 4 and 14 times higher than $\mathrm{PM}_{2.5-1.0}$ and $\mathrm{PM}_{1.0-0.3}$, respectively. During this winter period the sea salt sources, although from natural origin and strongly meteorologically driven, are enriched in the city in the form of sea salt resuspension from the roads.

Both direct emissions and resuspension have been identified above as important sources of trace elements. The trend in coarse aged sea salt across the three sites provides insight into the relative importance of these processes. We assume that all aged sea salt originates from a regional, siteindependent source, and that the concentration gradient in this factor between sites thus reflects the effect of local resuspension processes of naturally deposited aged sea salt. 

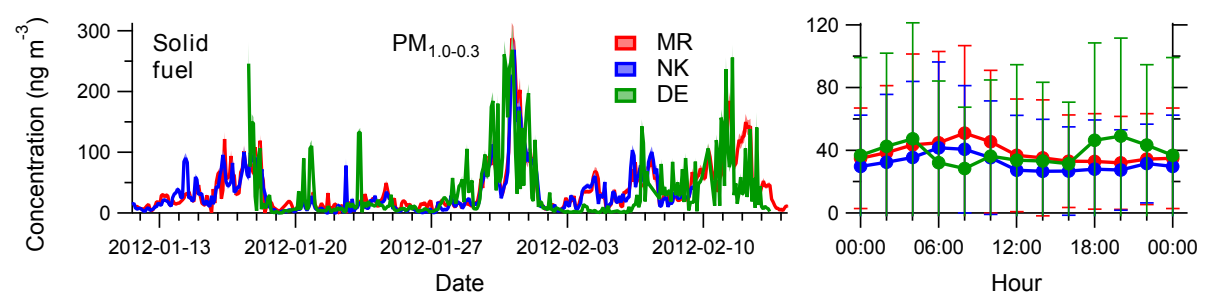

Figure 12. Time series (left) and diurnal variations (right) of the solid fuel factor at MR, NK and DE for PM $1.0-0.3$. Time series show the mean of all good solutions $\pm 1 \mathrm{SD}$ as shaded areas. Diurnals show the mean of the time series $\pm 1 \mathrm{SD}$ as whiskers, with the hour being the start of a $2 \mathrm{~h}$ sampling period (00:00 UTC means sampling from 00:00 to 02:00 UTC).

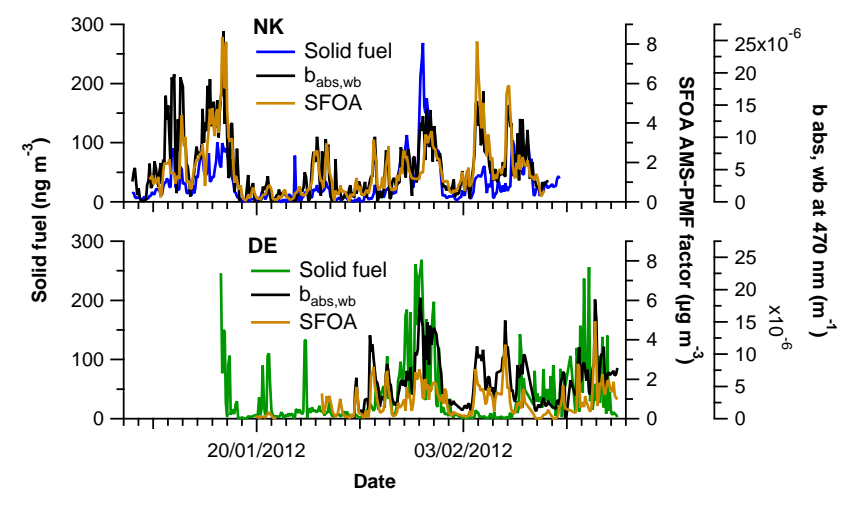

Figure 13. Time series of the solid fuel factor at NK and DE compared to the Aethalometer wood burning absorption coefficient at wavelength $470 \mathrm{~nm}$ ( $b_{\mathrm{abs}}$, wb at $\left.470 \mathrm{~nm}\right)$ and to the solid fuel organic aerosol (SFOA) factors resolved with AMS-PMF.

Although sea salt emissions are typically considered a natural process, human activities (vehicle-induced resuspension) enhance the concentrations of the coarse aged sea salt by 1.7-2.2 in the city relative to the rural site (Fig. 15). These ratios provide an upper limit for the resuspension enhancement (and thus a lower limit for the enhancement due to direct emissions) for the anthropogenically influenced factors, whose concentrations at DE may already be increased by local emissions. The lower limits for direct emission enhancement ratios in the coarse fraction at MR relative to DE are 3.5 to 12.7 for brake wear, other traffic-related, dust and sea/road salt factors (1.4-5.5 for NK / DE). Direct emissions for the traffic-related factor show similar enhancement in all size fractions, whereas enhancement of the other anthropogenically influenced factors are a factor of 1.5-3.0 lower in the smaller size fractions. These results indicate that direct source emission processes occur mainly for coarse particles and are dependent on the micro-environment. The S-rich and solid fuel factors have negligible resuspension influences (similar concentrations across sites). Air quality in London can be improved by the development of policies aiming to reduce resuspension processes.

Trace elements are often used as chemically conserved source markers. Here we assess the ability of elements mea- sured herein to serve as unique tracers for specific sources. For a tracer to be considered good, we require that a given source has a high relative contribution $(>70 \%)$ to a specific element, i.e. that the element is mainly attributed to a single source (Fig. 3). We suggest $\mathrm{Cu}, \mathrm{Zr}$, Sb or $\mathrm{Ba}$ as markers for brake wear in $\mathrm{PM}_{10-2.5}$ and $\mathrm{PM}_{2.5-1.0}$. The relative contributions are $>93,83,93$ and $96 \%$ for $\mathrm{Cu}, \mathrm{Zr}, \mathrm{Sb}$ and $\mathrm{Ba}$, respectively. The attribution of these elements to the traffic factor in $\mathrm{PM}_{1.0-0.3}$ with relative contributions between 69 and $84 \%$ also suggests brake wear emissions in this size fraction. $\mathrm{Fe}$ is typically also attributed to brake wear emissions (Amato et al., 2009b; Bukowiecki et al., 2010; Harrison et al., 2012b). However, we observed no Fe in the brake wear factors; instead 86 and $65 \%$ of Fe were attributed to other trafficrelated processes in $\mathrm{PM}_{10-2.5}$ and $\mathrm{PM}_{2.5-1.0}$ (74\% of Fe to the traffic-related factor in $\left.\mathrm{PM}_{1.0-0.3}\right)$. Furthermore, around $19 \%$ of $\mathrm{Fe}$ contributed to the resuspended dust factors in all three size fractions. We therefore recommend attributing $\mathrm{Fe}$ only to a specific source in combination with other markers. $\mathrm{Si}$ and $\mathrm{Ca}$ in all size fractions can be used as a surrogate for resuspended dust with relative contributions between 72 and $75 \%$ for $\mathrm{Si}$ and between 80 and $85 \%$ for $\mathrm{Ca}$. Coarse and intermediate fraction $\mathrm{Cl}$ (relative contributions $>87 \%$ ) are markers for fresh sea salt (preferably combined with $\mathrm{Na}$ and $\mathrm{Mg}$ ), while fine-fraction $\mathrm{Cl}$ is not a unique source indicator. Depending on the data set it can indicate waste incineration (Moffet et al., 2008), coal combustion (Yao et al., 2002) or reacted $\mathrm{Cl}$ as $\mathrm{NH}_{4} \mathrm{Cl}$ particles (current study, relative contribution $59 \%$ ). A combination of fine-fraction $\mathrm{K}$ and $\mathrm{Pb}$ with relative contributions of around $80 \%$ indicates solid fuel in this study, but can also be attributed to wood, coal or peat burning separately. Fine-fraction $\mathrm{S}$ can typically be attributed to regionally transported secondary sulfate (here only a $65 \%$ relative contribution). Other elements can also be used as source markers, but rather as a combination of elements than individually, and preferably combined with measurements of other species.

The analysis herein clearly shows the advantages of rotationally controlled analyses relative to an unconstrained PMF solution. Supplement Figs. S1-S4 show the best solutions retrieved from unconstrained analyses for the separate size fractions (four-, four-, and five-factor solutions for $\mathrm{PM}_{10-2.5}$, 

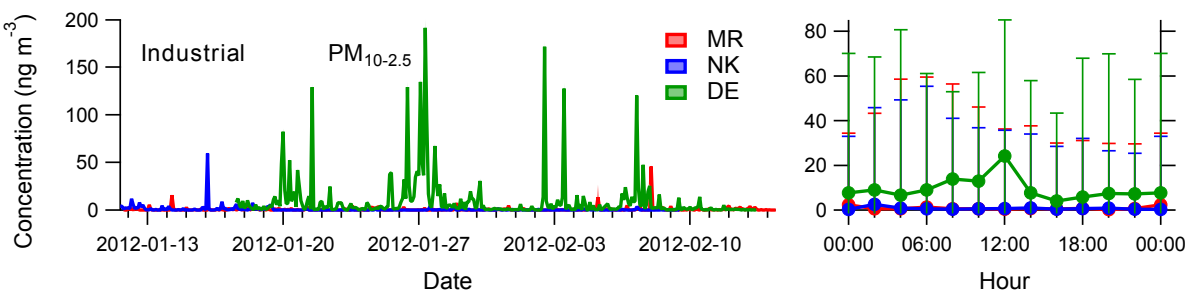

Figure 14. Time series (left) and diurnal variations (right) of the industrial factor at MR, NK and DE for PM $10-2.5$. Time series show the mean of all good solutions $\pm 1 \mathrm{SD}$ as shaded areas. Diurnals show the mean of the time series $\pm 1 \mathrm{SD}$ as whiskers, with the hour being the start of a $2 \mathrm{~h}$ sampling period (00:00 UTC means sampling from 00:00 to 02:00 UTC).

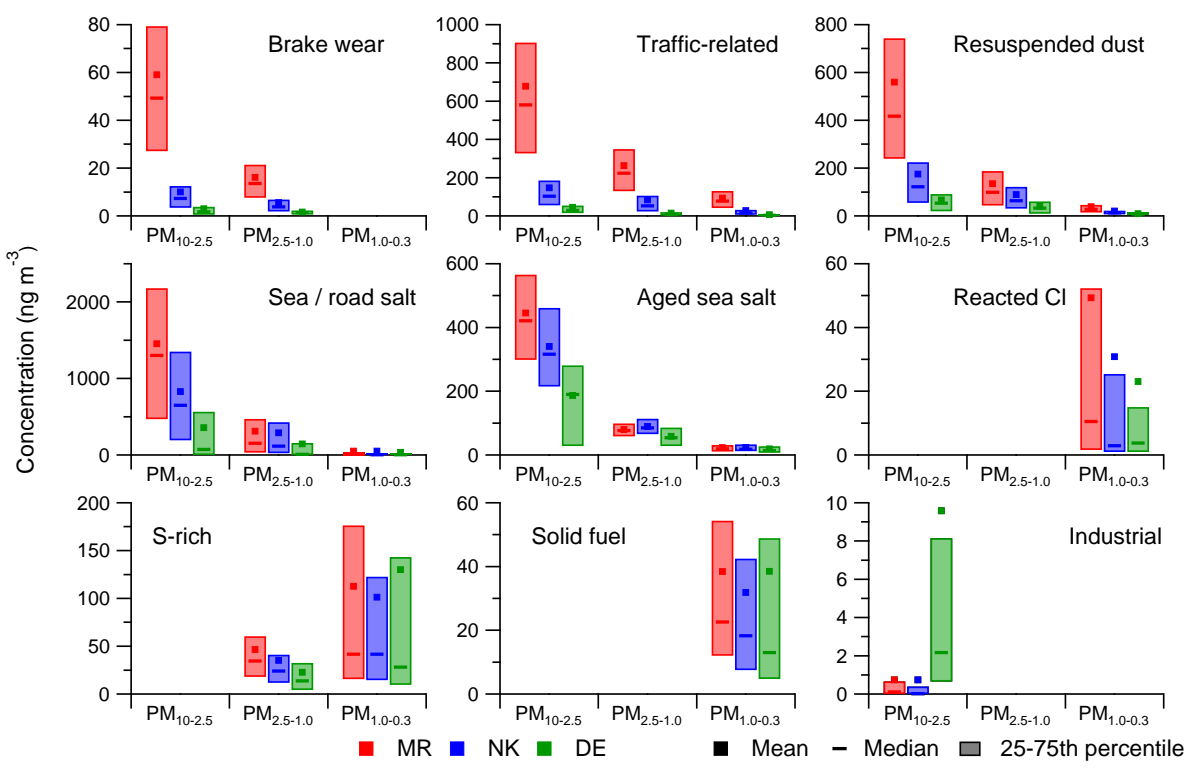

Figure 15. Mean, median and 25-75th percentile concentrations of the nine different ME-2 factor time series at MR, NK and DE for $\mathrm{PM}_{10-2.5}, \mathrm{PM}_{2.5-1.0}$ and $\mathrm{PM}_{1.0-0.3}$. Note that not all factors are retrieved in all size fractions.

$\mathrm{PM}_{2.5-1.0}$, and $\mathrm{PM}_{1.0-0.3}$, respectively). The unconstrained $\mathrm{PM}_{10-2.5}$ solution (Supplement Figs. S1 and S4) yields high residuals of $\mathrm{Ni}, \mathrm{Cr}$, and $\mathrm{Mo}$ and does not resolve a brake wear factor. The unconstrained $\mathrm{PM}_{2.5-1.0}$ solution (Supplement Figs. S2 and S4) likewise does not yield brake wear and additionally fails to resolve aged (reacted) sea salt from regionally transported sulfate and solid fuel, despite strong evidence for this processing in the raw time series. Finally, the unconstrained $\mathrm{PM}_{1.0-0.3}$ solution (Supplement Figs. S3 and S4) mixes secondary sulfur and solid fuel sources. It also fails to explain major events contained in the Cl-rich factor, apportioning significant $\mathrm{Na}$ to these events, leading to high Na residuals. Higher-order solutions do not resolve these problems, instead leading to uninterpretable splitting of the dust factor, factors consisting only of single elements, and unstable solutions that are highly dependent on algorithm initialization (seed).

\section{Conclusions}

Trace element measurements were performed at kerbside, urban background and rural sites to characterize the environment-dependent variability of emissions in the European megacity of London during winter 2012. Sampling with rotating drum impactors and subsequent synchrotron radiation-induced $\mathrm{X}$-ray fluorescence spectrometry yielded $2 \mathrm{~h}$ element mass concentrations in $\mathrm{PM}_{10-2.5}, \mathrm{PM}_{2.5-1.0}$ and $\mathrm{PM}_{1.0-0.3}$ aerosol. Source apportionment using the ME-2 algorithm in the PMF model was conducted on data sets comprising all three sites but analysed separately for each size. Combining the sites enabled separation of sources with high temporal covariance but significant spatial variability. Separation of sizes improved source resolution by preventing sources occurring in only a single size fraction from having too small a contribution for the model to resolve. Anchor profiles for several factors were retrieved by analysing specific data subsets and these profiles were successfully used in 
the analyses of the complete data sets to retrieve clean factor profiles and time series at all sites.

The coarse fraction yielded (elements with highest relative contributions in brackets) brake wear $(\mathrm{Cu}, \mathrm{Zr}, \mathrm{Sb}, \mathrm{Ba})$, other traffic-related $(\mathrm{Fe})$, resuspended dust $(\mathrm{Si}, \mathrm{Ca})$, sea/road salt $(\mathrm{Cl})$, aged sea salt $(\mathrm{Na}, \mathrm{Mg})$ and industrial $(\mathrm{Cr}, \mathrm{Ni})$ factors. The intermediate fraction yielded the same factors except for the industrial, instead yielding an $\mathrm{S}$-rich $(\mathrm{S})$ factor. In the fine fraction a traffic-related factor $(\mathrm{Fe}, \mathrm{Cu}, \mathrm{Zr}, \mathrm{Sb}, \mathrm{Ba})$ was found as well as resuspended dust, sea/road salt, aged sea salt, reacted $\mathrm{Cl}(\mathrm{Cl})$, S-rich and solid fuel $(\mathrm{K}, \mathrm{Pb})$. The other analysed elements (Al, P, Ti, V, Mn, Zn, Br, Sr, Mo, Sn) could not be attributed to a single factor. The brake wear, industrial, reacted $\mathrm{Cl}$ and solid fuel factors could only be resolved with the help of anchor profiles retrieved internally in the data sets. Unconstrained ME-2 only led to mixed traffic-related/brake wear, resuspended dust, sea/road salt and aged sea salt factors in the coarse fraction; to mixed traffic-related/brake wear, resuspended dust, sea/road salt and mixed aged sea salt/regional transport factors in the intermediate fraction; and to traffic-related, resuspended dust, aged sea salt, mixed $\mathrm{S}$-rich/solid fuel and mixed sea/road salt/Cl-rich factors in the fine fraction.

The regionally influenced S-rich and solid fuel factors are restricted to the smaller size fractions, and have similar concentrations throughout the day and across larger regions. The locally influenced sources show major heterogeneity in human exposure patterns within different microenvironments. The brake wear, other traffic-related and resuspended dust sources show steep concentration gradients from kerbside to urban background to rural sites and from $\mathrm{PM}_{10-2.5}$ to $\mathrm{PM}_{2.5-1.0}$ to $\mathrm{PM}_{1.0-0.3}$ (ratios up to 28 and 14 for kerb-to-rural and $\mathrm{PM}_{10-2.5}$-to- $\mathrm{PM}_{1.0-0.3}$, respectively) and are directly related to anthropogenic activities (mainly traffic flows) with concentrations up to a factor of 4 higher during daytime relative to night-time. The relative mass contributions are dominated by the sea salt factors in $\mathrm{PM}_{10-2.5}$ and $\mathrm{PM}_{2.5-1.0}$, while the regionally influenced factors dominate $\mathrm{PM}_{1.0-0.3}$.

The site-dependent concentration gradients in aged sea salt reflect the effect of local resuspension processes. Human activities enhance the kerbside concentrations of the coarse aged sea salt by a factor of 1.7-2.2 compared with the rural site. For anthropogenically influenced factors, direct source emissions provide a further kerb-to-rural enhancement of concentrations by a factor of 3.5-12.7, and these direct emissions occur mainly for coarse particles.

The Supplement related to this article is available online at doi:10.5194/acp-15-11291-2015-supplement.
Acknowledgements. We thank the Swiss National Science Foundation (SNSF grant 200021_132467/1), the UK Natural Environment Research Council (NERC) ClearfLo consortium (NERC grant NE/H00324X/1, NE/H0081368/1), and the European Community's Seventh Framework Programme (FP/2007-2013, grant number 312284). J. G. Slowik was supported by the SNSF Ambizione programme (grant PX00P2_31673), and D. E. Young by a NERC PhD studentship (grant NE/I528142/1). The Detling site was supported by the US Department of Energy Atmospheric Systems Research Program (DOE award no. DE-SC0006002). We thank Empa for the RDI they loaned us during the ClearfLo project. Parts of the work were carried out at the Swiss Light Source, Paul Scherrer Institute, Villigen, Switzerland. We thank Andreas Jaggi and Christophe Frieh for technical support at the beamline X05DA. Parts of the study were also performed at the light source facility DORIS III at HASYLAB/DESY. DESY is a member of the Helmholtz Association (HGF).

Edited by: X. Querol

\section{References}

Amato, F., Pandolfi, M., Escrig, A., Querol, X., Alastuey, A., Pey, J., Perez, N., and Hopke, P. K.: Quantifying road dust resuspension in urban environment by Multilinear Engine: A comparison with PMF2, Atmos. Environ., 43, 2770-2780, 2009a.

Amato, F., Pandolfi, M., Viana, M., Querol, X., Alastuey, A., and Moreno, T.: Spatial and chemical patterns of $\mathrm{PM}_{10}$ in road dust deposited in urban environment, Atmos. Environ., 43, 16501659, 2009b.

Amato, F., Schaap, M., Denier van der Gon, H. A. C., Pandolfi, M., Alastuey, A., Keuken, M., and Querol, X.: Short-term variability of mineral dust, metals and carbon emission from road dust resuspension, Atmos. Environ., 74, 134-140, 2013.

Bigi, A. and Harrison, R. M.: Analysis of the air pollution climate at a central urban background site, Atmos. Environ., 44, 20042012, 2010.

Bohnenstengel, S. I., Belcher, S. E., Aiken, A., Allan, J. D., Allen, G., Bacak, A., Bannan, T. J., Barlow, J. F., Beddows, D. C. S., Bloss, W. J., Booth, A. M., Chemel, C., Coceal, O., Di Marco, C. F., Dubey, M. K., Faloon, K. H., Fleming, Z. L., Furger, M., Gietl, J. K., Graves, R. R., Green, D. C., Grimmond, C. S. B., Halios, C. H., Hamilton, J. F., Harrison, R. M., Heal, M. R., Heard, D. E., Helfter, C., Herndon, S. C., Holmes, R. E., Hopkins, J. R., Jones, A. M., Kelly, F. J., Kotthaus, S., Langford, B., Lee, J. D., Leigh, R. J., Lewis, A. C., Lidster, R. T., LopezHilfiker, F. D., McQuaid, J. B., Mohr, C., Monks, P. S., Nemitz, E., Ng, N. L., Percival, C. J., Prévôt, A. S. H., Ricketts, H. M. A., Sokhi, R., Stone, D., Thornton, J. A., Tremper, A. H., Valach, A. C., Visser, S., Whalley, L. K., Williams, L. R., Xu, L., Young, D. E., and Zotter, P.: Meteorology, air quality, and health in London: The ClearfLo project, B. Am. Meteorol. Soc., 96, 779-804, 2015.

Brunekreef, B. and Forsberg, B.: Epidemiological evidence of effects of coarse airborne particles on health, Eur. Respir. J., 26, 309-318, 2005.

Bukowiecki, N., Lienemann, P., Hill, M., Figi, R., Richard, A., Furger, M., Rickers, K., Falkenberg, G., Zhao, Y. J., Cliff, S. S., 
Prévôt, A. S. H., Baltensperger, U., Buchmann, B., and Gehrig, R.: Real-world emission factors for antimony and other brake wear related trace elements: Size-segregated values for light and heavy duty vehicles, Environ. Sci. Technol., 43, 8072-8078, 2009.

Bukowiecki, N., Lienemann, P., Hill, M., Furger, M., Richard, A., Amato, F., Prévôt, A. S. H., Baltensperger, U., Buchmann, B., and Gehrig, R.: $\mathrm{PM}_{10}$ emission factors for non-exhaust particles generated by road traffic in an urban street canyon and along a freeway in Switzerland, Atmos. Environ., 44, 2330-2340, 2010.

Canonaco, F., Crippa, M., Slowik, J. G., Baltensperger, U., and Prévôt, A. S. H.: SoFi, an IGOR-based interface for the efficient use of the generalized multilinear engine (ME-2) for the source apportionment: ME-2 application to aerosol mass spectrometer data, Atmos. Meas. Tech., 6, 3649-3661, doi:10.5194/amt6-3649-2013, 2013.

Charron, A. and Harrison, R. M.: Fine $\left(\mathrm{PM}_{2.5}\right)$ and coarse $\left(\mathrm{PM}_{2.5-10}\right)$ particulate matter on a heavily trafficked London highway: Sources and processes, Environ. Sci. Technol., 39, 7768-7776, 2005.

Clements, N., Eav, J., Xie, M., Hannigan, M. P., Miller, S. L., Navidi, W., Peel, J. L., Schauer, J. J., Shafer, M. M., and Milford, J. B.: Concentrations and source insights for trace elements in fine and coarse particulate matter, Atmos. Environ., 89, 373-381, 2014.

Crilley, L. R., Bloss, W. J., Yin, J., Beddows, D. C. S., Harrison, R. M., Allan, J. D., Young, D. E., Flynn, M., Williams, P., Zotter, P., Prevot, A. S. H., Heal, M. R., Barlow, J. F., Halios, C. H., Lee, J. D., Szidat, S., and Mohr, C.: Sources and contributions of wood smoke during winter in London: assessing local and regional influences, Atmos. Chem. Phys., 15, 3149-3171, doi:10.5194/acp15-3149-2015, 2015.

Cuccia, E., Bernardoni, V., Massabò, D., Prati, P., Valli, G., and Vecchi, R.: An alternative way to determine the size distribution of airborne particulate matter, Atmos. Environ., 44, 3304-3313, 2010.

Dall'Osto, M., Querol, X., Amato, F., Karanasiou, A., Lucarelli, F., Nava, S., Calzolai, G., and Chiari, M.: Hourly elemental concentrations in $\mathrm{PM}_{2.5}$ aerosols sampled simultaneously at urban background and road site during SAPUSS - diurnal variations and PMF receptor modelling, Atmos. Chem. Phys., 13, 43754392, doi:10.5194/acp-13-4375-2013, 2013.

DeCarlo, P. F., Kimmel, J. R., Trimborn, A., Northway, M. J., Jayne, J. T., Aiken, A. C., Gonin, M., Fuhrer, K., Horvath, T., Docherty, K. S., Worsnop, D. R., and Jimenez, J. L.: Field-deployable, high-resolution, time-of-flight aerosol mass spectrometer, Anal. Chem., 78, 8281-8289, 2006.

Denier van der Gon, H., Gerlofs-Nijland, M. E., Gehrig, R., Gustafsson, M., Janssen, N., Harrison, R. M., Hulskotte, J., Johansson, C., Jozwicka, M., Keuken, M., Krijgsheld, K., Ntziachristos, L., Riediker, M., and Cassee, F. R.: The policy relevance of wear emissions from road transport, now and in the future: An international workshop report and consensus statement, J. Air Waste Manage., 63, 136-149, 2013.

Department for Transport: Traffic counts, available at: http://www. dft.gov.uk/traffic-counts/cp.php (last access: 30 October 2012), 2014.

Detournay, A., Di Marco, C., Langford, B., Green, D., Tremper, A., and Nemitz, E.: Seasonal variation in submicron aerosol chem- ical components at a London roadside site and their controls, in preparation, 2015.

DeWees, W. G., Segall, R. R., Cone, L., and Lewis, F. M.: Emissions of metals, chromium and nickel species, and organics from municipal wastewater sludge incinerators, Report, United States Environmental Protection Agency, Cincinnati, OH, 1992.

EEA: The European environment - state and outlook 2010: synthesis, Report, European Environment Agency, Copenhagen, 2010.

Flechsig, U., Jaggi, A., Spielmann, S., Padmore, H. A., and MacDowell, A. A.: The optics beamline at the Swiss Light Source, Nucl. Instrum. Meth. A, 609, 281-285, 2009.

Gu, J. W., Pitz, M., Schnelle-Kreis, J., Diemer, J., Reller, A., Zimmermann, R., Soentgen, J., Stoelzel, M., Wichmann, H. E., Peters, A., and Cyrys, J.: Source apportionment of ambient particles: Comparison of positive matrix factorization analysis applied to particle size distribution and chemical composition data, Atmos. Environ., 45, 1849-1857, 2011.

Hammond, D. M., Dvonch, J. T., Keeler, G. J., Parker, E. A., Kamal, A. S., Barres, J. A., Yip, F. Y., and Brakefield-Caldwell, W.: Sources of ambient fine particulate matter at two community sites in Detroit, Michigan, Atmos. Environ., 42, 720-732, 2008.

Handler, M., Puls, C., Zbiral, J., Marr, I., Puxbaum, H., and Limbeck, A.: Size and composition of particulate emissions from motor vehicles in the Kaisermuhlen-Tunnel, Vienna, Atmos. Environ., 42, 2173-2186, 2008.

Harrison, R. M. and Jones, A. M.: Multisite study of particle number concentrations in urban air, Environ. Sci. Technol., 39, 60636070, 2005.

Harrison, R. M., Stedman, J., and Derwent, D.: New directions: Why are $\mathrm{PM}_{10}$ concentrations in Europe not falling?, Atmos. Environ., 42, 603-606, 2008.

Harrison, R. M., Beddows, D. C. S., Hu, L., and Yin, J.: Comparison of methods for evaluation of wood smoke and estimation of UK ambient concentrations, Atmos. Chem. Phys., 12, 82718283, doi:10.5194/acp-12-8271-2012, 2012a.

Harrison, R. M., Jones, A. M., Gietl, J., Yin, J., and Green, D. C.: Estimation of the contributions of brake dust, tire wear, and resuspension to nonexhaust traffic particles derived from atmospheric measurements, Environ. Sci. Technol., 46, 6523-6529, $2012 b$.

Jimenez, J. L., Canagaratna, M. R., Donahue, N. M., Prevot, A. S. H., Zhang, Q., Kroll, J. H., DeCarlo, P. F., Allan, J. D., Coe, H., Ng, N. L., Aiken, A. C., Docherty, K. S., Ulbrich, I. M., Grieshop, A. P., Robinson, A. L., Duplissy, J., Smith, J. D., Wilson, K. R., Lanz, V. A., Hueglin, C., Sun, Y. L., Tian, J., Laaksonen, A., Raatikainen, T., Rautiainen, J., Vaattovaara, P., Ehn, M., Kulmala, M., Tomlinson, J. M., Collins, D. R., Cubison, M. J., E., Dunlea, J., Huffman, J. A., Onasch, T. B., Alfarra, M. R., Williams, P. I., Bower, K., Kondo, Y., Schneider, J., Drewnick, F., Borrmann, S., Weimer, S., Demerjian, K., Salcedo, D., Cottrell, L., Griffin, R., Takami, A., Miyoshi, T., Hatakeyama, S., Shimono, A., Sun, J. Y., Zhang, Y. M., Dzepina, K., Kimmel, J. R., Sueper, D., Jayne, J. T., Herndon, S. C., Trimborn, A. M., Williams, L. R., Wood, E. C., Middlebrook, A. M., Kolb, C. E., Baltensperger, U., and Worsnop, D. R.: Evolution of organic aerosols in the atmosphere, Science, 326, 1525-1529, 2009.

Jones, A. M., Harrison, R. M., and Baker, J.: The wind speed dependence of the concentrations of airborne particulate matter and $\mathrm{NO}_{x}$, Atmos. Environ., 44, 1682-1690, 2010. 
Jones, A. R., Thomson, D. J., Hort, M., and Devenish, B.: The UK Met Office's next-generation atmospheric dispersion model, NAME III, Air Pollution Modeling and its Application XVII, Springer, Exeter, UK, 2007.

Karanasiou, A. A., Siskos, P. A., and Eleftheriadis, K.: Assessment of source apportionment by Positive Matrix Factorization analysis on fine and coarse urban aerosol size fractions, Atmos. Environ., 43, 3385-3395, 2009.

Mazzei, F., Lucarelli, F., Nava, S., Prati, P., Valli, G., and Vecchi, R.: A new methodological approach: the combined use of twostage streaker samplers and optical particle counters for the characterization of airborne particulate matter, Atmos. Environ., 41, 5525-5535, 2007.

Minguillón, M. C., Cirach, M., Hoek, G., Brunekreef, B., Tsai, M., de Hoogh, K., Jedynska, A., Kooter, I. M., Nieuwenhuijsen, M., and Querol, X.: Spatial variability of trace elements and sources for improved exposure assessment in Barcelona, Atmos. Environ., 89, 268-281, 2014.

Moffet, R. C., Desyaterik, Y., Hopkins, R. J., Tivanski, A. V., Gilles, M. K., Wang, Y., Shutthanandan, V., Molina, L. T., Abraham, R. G., Johnson, K. S., Mugica, V., Molina, M. J., Laskin, A., and Prather, K. A.: Characterization of aerosols containing $\mathrm{Zn}, \mathrm{Pb}$, and $\mathrm{Cl}$ from an industrial region of Mexico City, Environ. Sci. Technol., 42, 7091-7097, 2008.

Mohr, C., Lopez-Hilfiker, F. D., Zotter, P., Prévôt, A. S. H., Xu, L., Ng, N. L., Herndon, S. C., Williams, L. R., Franklin, J. P., Zahniser, M. S., Worsnop, D. R., Knighton, W. B., Aiken, A. C., Gorkowski, K. J., Dubey, M. K., Allan, J. D., and Thornton, J. A.: Contribution of nitrated phenols to wood burning brown carbon light absorption in Detling, United Kingdom during winter time, Environ. Sci. Technol., 47, 6316-6324, 2013.

Moreno, T., Querol, X., Alastuey, A., Reche, C., Cusack, M., Amato, F., Pandolfi, M., Pey, J., Richard, A., Prévôt, A. S. H., Furger, M., and Gibbons, W.: Variations in time and space of trace metal aerosol concentrations in urban areas and their surroundings, Atmos. Chem. Phys., 11, 9415-9430, doi:10.5194/acp-11-94152011, 2011.

Neuberger, M., Schimek, M. G., Horak Jr., F., Moshammer, H., Kundi, M., Frischer, T., Gomiscek, B., Puxbaum, H., and Hauck, H.: Acute effects of particulate matter on respiratory diseases, symptoms and functions: epidemiological results of the Austrian Project on Health Effects of Particulate Matter (AUPHEP), Atmos. Environ., 38, 3971-3981, 2004.

Paatero, P.: The multilinear engine - A table-driven, least squares program for solving multilinear problems, including the n-way parallel factor analysis model, J. Comput. Graph. Stat., 8, 854888, 1999.

Paatero, P. and Hopke, P. K.: Discarding or downweighting highnoise variables in factor analytic models, Anal. Chim. Acta, 490, 277-289, 2003.

Paatero, P. and Tapper, U.: Analysis of different modes of factoranalysis as least-squares fit problems, Chemometr. Intell. Lab., 18, 183-194, 1993.

Paatero, P. and Tapper, U.: Positive matrix factorization: A nonnegative factor model with optimal utilization of error estimates of data values, Environmetrics, 5, 111-126, 1994.

Paatero, P., Hopke, P. K., Song, X. H., and Ramadan, Z.: Understanding and controlling rotations in factor analytic models, Chemometr. Intell. Lab., 60, 253-264, 2002.
Pant, P. and Harrison, R. M.: Estimation of the contribution of road traffic emissions to particulate matter concentrations from field measurements: A review, Atmos. Environ., 77, 78-97, 2013.

Querol, X., Viana, M., Alastuey, A., Amato, F., Moreno, T., Castillo, S., Pey, J., de la Rosa, J., Sánchez de la Campa, A., Artíñano, B., Salvador, P., García Dos Santos, S., Fernández-Patier, R., Moreno-Grau, S., Negral, L., Minguillón, M. C., Monfort, E., Gil, J. I., Inza, A., Ortega, L. A., Santamaría, J. M., and Zabalza, J.: Source origin of trace elements in PM from regional background, urban and industrial sites of Spain, Atmos. Environ., 41, 7219-7231, 2007.

Richard, A., Gianini, M. F. D., Mohr, C., Furger, M., Bukowiecki, N., Minguillón, M. C., Lienemann, P., Flechsig, U., Appel, K., DeCarlo, P. F., Heringa, M. F., Chirico, R., Baltensperger, U., and Prévôt, A. S. H.: Source apportionment of size and time resolved trace elements and organic aerosols from an urban courtyard site in Switzerland, Atmos. Chem. Phys., 11, 8945-8963, doi:10.5194/acp-11-8945-2011, 2011.

Rudnick, R. and Gao, S.: Composition of the continental crust, in: The Crust, Vol. 3, edited by: Rudnick, E., Book Section 2, 1-56, Elsevier Science, Philadelphia, 2003.

Sandradewi, J., Prévôt, A. S. H., Szidat, S., Perron, N., Alfarra, M. R., Lanz, V. A., Weingartner, E., and Baltensperger, U.: Using aerosol light absorption measurements for the quantitative determination of wood burning and traffic emission contributions to particulate matter, Environ. Sci. Technol., 42, 3316-3323, 2008.

Seinfeld, J. H. and Pandis, S. N.: Atmospheric Chemistry and Physics: From Air Pollution To Climate Change, John Wiley \& Sons, Inc., New Jersey, 2nd Edn., 2006.

Sturtz, T. M., Adar, S. D., Gould, T., and Larson, T. V.: Constrained source apportionment of coarse particulate matter and selected trace elements in three cities from the multi-ethnic study of atherosclerosis, Atmos. Environ., 84, 65-77, 2014.

Taiwo, A. M., Beddows, D. C., Calzolai, G., Harrison, R. M., Lucarelli, F., Nava, S., Shi, Z., Valli, G., and Vecchi, R.: Receptor modelling of airborne particulate matter in the vicinity of a major steelworks site, Sci. Total Environ., 490, 488-500, 2014.

Twigg, M. M., Di Marco, C. F., Leeson, S., van Dijk, N., Jones, M. R., Leith, I. D., Morrison, E., Coyle, M., Proost, R., Peeters, A. N. M., Lemon, E., Frelink, T., Braban, C. F., Nemitz, E., and Cape, J. N.: Water soluble aerosols and gases at a UK background site - Part 1: Controls of $\mathrm{PM}_{2.5}$ and $\mathrm{PM}_{10}$ aerosol composition, Atmos. Chem. Phys., 15, 8131-8145, doi:10.5194/acp-15-81312015, 2015.

Vedal, S., Hannigan, M. P., Dutton, S. J., Miller, S. L., Milford, J. B., Rabinovitch, N., Kim, S. Y., and Sheppard, L.: The Denver Aerosol Sources and Health (DASH) study: Overview and early findings, Atmos. Environ., 43, 1666-1673, 2009.

Viana, M., Querol, X., Götschi, T., Alastuey, A., Sunyer, J., Forsberg, B., Heinrich, J., Norbäck, D., Payo, F., Maldonado, J. A., and Künzli, N.: Source apportionment of ambient $\mathrm{PM}_{2.5}$ at five spanish centres of the European community respiratory health survey (ECRHS II), Atmos. Environ., 41, 1395-1406, 2007.

Viana, M., Kuhlbusch, T. A. J., Querol, X., Alastuey, A., Harrison, R. M., Hopke, P. K., Winiwarter, W., Vallius, A., Szidat, S., Prevot, A. S. H., Hueglin, C., Bloemen, H., Wahlin, P., Vecchi, R., Miranda, A. I., Kasper-Giebl, A., Maenhaut, W., and Hitzenberger, R.: Source apportionment of particulate matter in Europe: 
A review of methods and results, J. Aerosol Sci. 39, 827-849, 2008.

Viana, M., Reche, C., Amato, F., Alastuey, A., Querol, X., Moreno, T., Lucarelli, F., Nava, S., Cazolai, G., Chiari, M., and Rico, M.: Evidence of biomass burning aerosols in the Barcelona urban environment during winter time, Atmos. Environ., 72, 81-88, 2013.

Visser, S., Slowik, J. G., Furger, M., Zotter, P., Bukowiecki, N., Dressler, R., Flechsig, U., Appel, K., Green, D. C., Tremper, A. H., Young, D. E., Williams, P. I., Allan, J. D., Herndon, S. C., Williams, L. R., Mohr, C., Xu, L., Ng, N. L., Detournay, A., Barlow, J. F., Halios, C. H., Fleming, Z. L., Baltensperger, U., and Prévôt, A. S. H.: Kerb and urban increment of highly time-resolved trace elements in $\mathrm{PM}_{10}, \mathrm{PM}_{2.5}$ and $\mathrm{PM}_{1.0}$ winter aerosol in London during ClearfLo 2012, Atmos. Chem. Phys., 15, 2367-2386, doi:10.5194/acp-15-2367-2015, 2015.

Walterson, E.: Chromium, nickel and molybdenum in society and the environment; A complication of facts on flows, quantities and effects in Sweden, Report, Reference Group for Metals Surveys, Stockholm, 1998.

Wedepohl, K.: The composition of the continental crust, Geochim. Cosmochim. Ac., 59, 1217-1232, 1995.

WHO: Review of evidence on health aspects of air pollution - REVIHAAP Project, Report, WHO European Centre for Environment and Health, Bonn, 2013.

WHO: World Health Statistics 2014, Report, World Health Organization, Geneva, 2014.

Witt, M. L. I., Meheran, N., Mather, T. A., de Hoog, J. C. M., and Pyle, D. M.: Aerosol trace metals, particle morphology and total gaseous mercury in the atmosphere of Oxford, UK, Atmos. Environ., 44, 1524-1538, 2010.

Wood, C. R., Lacser, A., Barlow, J. F., Padhra, A., Belcher, S. E., Nemitz, E., Helfter, C., Famulari, D., and Grimmond, C. S. B.: Turbulent flow at $190 \mathrm{~m}$ height above London during 2006-2008: A climatology and the applicability of similarity theory, Bound.Lay. Meteorol., 137, 77-96, 2010.
Yang, L., Cheng, S., Wang, X., Nie, W., Xu, P., Gao, X., Yuan, C., and Wang, W.: Source identification and health impact of $\mathrm{PM}_{2.5}$ in a heavily polluted urban atmosphere in China, Atmos. Environ., 75, 265-269, 2013.

Yao, X., Chan, C. K., Fang, M., Cadle, S., Chan, T., Mulawa, P., He, $\mathrm{K}$, and Ye, B.: The water-soluble ionic composition of $\mathrm{PM}_{2.5}$ in Shanghai and Beijing, China, Atmos. Environ., 36, 4223-4234, 2002.

Young, D. E., Allan, J. D., Williams, P. I., Green, D. C., Flynn, M. J., Harrison, R. M., Yin, J., Gallagher, M. W., and Coe, H.: Investigating the annual behaviour of submicron secondary inorganic and organic aerosols in London, Atmos. Chem. Phys., 15, 63516366, doi:10.5194/acp-15-6351-2015, 2015a.

Young, D. E., Allan, J. D., Williams, P. I., Green, D. C., Harrison, R. M., Yin, J., Flynn, M. J., Gallagher, M. W., and Coe, H.: Investigating a two-component model of solid fuel organic aerosol in London: processes, PM1 contributions, and seasonality, Atmos. Chem. Phys., 15, 2429-2443, doi:10.5194/acp-152429-2015, 2015b.

Zhang, Q., Jimenez, J. L., Canagaratna, M. R., Ulbrich, I. M., Ng, N. L., Worsnop, D. R., and Sun, Y. L.: Understanding atmospheric organic aerosols via factor analysis of aerosol mass spectrometry: a review, Anal. Bioanal. Chem., 401, 3045-3067, 2011.

Zhang, R., Jing, J., Tao, J., Hsu, S.-C., Wang, G., Cao, J., Lee, C. S. L., Zhu, L., Chen, Z., Zhao, Y., and Shen, Z.: Chemical characterization and source apportionment of $\mathrm{PM}_{2.5}$ in Beijing: seasonal perspective, Atmos. Chem. Phys., 13, 7053-7074, doi:10.5194/acp-13-7053-2013, 2013. 